\title{
К вопросу о восточнодардской языковой общности *
}

\begin{abstract}
Статья посвящена проблеме генетической классификации дардских языков. Особое внимание уделяется вопросу о генетических отношениях языков, традиционно называемых восточнодардскими. Для решения этого вопроса используются два различных лексикостатистических метода: разновидность метода «ближайших соседей» и статистический метод наименьших средних отклонений. Сравнительный анализ полученных генетических деревьев и их сопоставление с историческими свидетельствами позволяет сделать вывод о выделении восточнодардских языков в единую и обособленную ветвь внутри дардской группы.
\end{abstract}

Ключевые слова: дардские языки, генетическая классификация, историческая фонетика, этимология, лексикостатистика, метод «ближайших соседей».

Вопрос о генетической классификации дардских языков до сих пор остается неразрешенным, хотя попытки ее построения предпринимались уже достаточно давно. Первая такая попытка, как известно, была сделана еще в начале XX в. Дж. Грирсоном [Grierson 1919], предложившим выделить внутри дардской группы 3 подгруппы: кафирскую (объединявшую языки пашаи, гавар-бати, тирахи и калаша, а также 4 языка, ныне по историко-фонетическим критериям выделяемых в самостоятельную (нуристанскую) ветвь арийских языков - кати, вайгали, ашкун и прасун), центральную (представленную языком кховар) и восточнодардскую (включающую кашмири, шина, а также языки, объединяемые под общим названием кохистанских - башкарик ${ }^{1}$, торвали, майян, говро, чилиссо), рис. 1. В настоящее время данная классификационная схема считается рядом исследователей устаревшейㄹ. Большей популярностью при этом пользуется альтернативная классификация, предложенная Г. Моргенстьерне ${ }^{3}$. Согласно ей, дардские языки делятся на 6 подгрупп: читральскую (включающую языки кховар и калаша), кунарскую (языки гавар-бати, шумашти, глангали, нингалами и дамели), пашаи, кохистанскую (языки башкарик, торвали, майян, катаркалаи [вотапури] и тирахи), шина (диалекты языка шина и язык пхалура с диалектом сави) и кашмирскую (язык кашмири, включая диалекты, распространенные за пределами Кашмирской долины - каштавари, погули, сираджи и рамбани), рис. 2. Впоследствии в классификацию Г. Моргенстьерне были внесены незначительные изменения - языки тирахи и катаркалаи были выведены из числа кохистанских и выделены в самостоятельные ветви, а язык дамели - напротив, включен в кохистанскую подгруппу [Strand 2006].

* Материалы, представленные в лексикостатистической части статьи, подготовлены при поддержке гранта РФФИ №12-06-00214.

${ }^{1}$ Известен также под названиями дири, гарви, гаври и калам-кохистани.

${ }^{2}$ См., напр., [Strand 1973, 2006].

${ }^{3}$ Она приведена, напр., в поздней работе [Morgenstierne 1961]. 


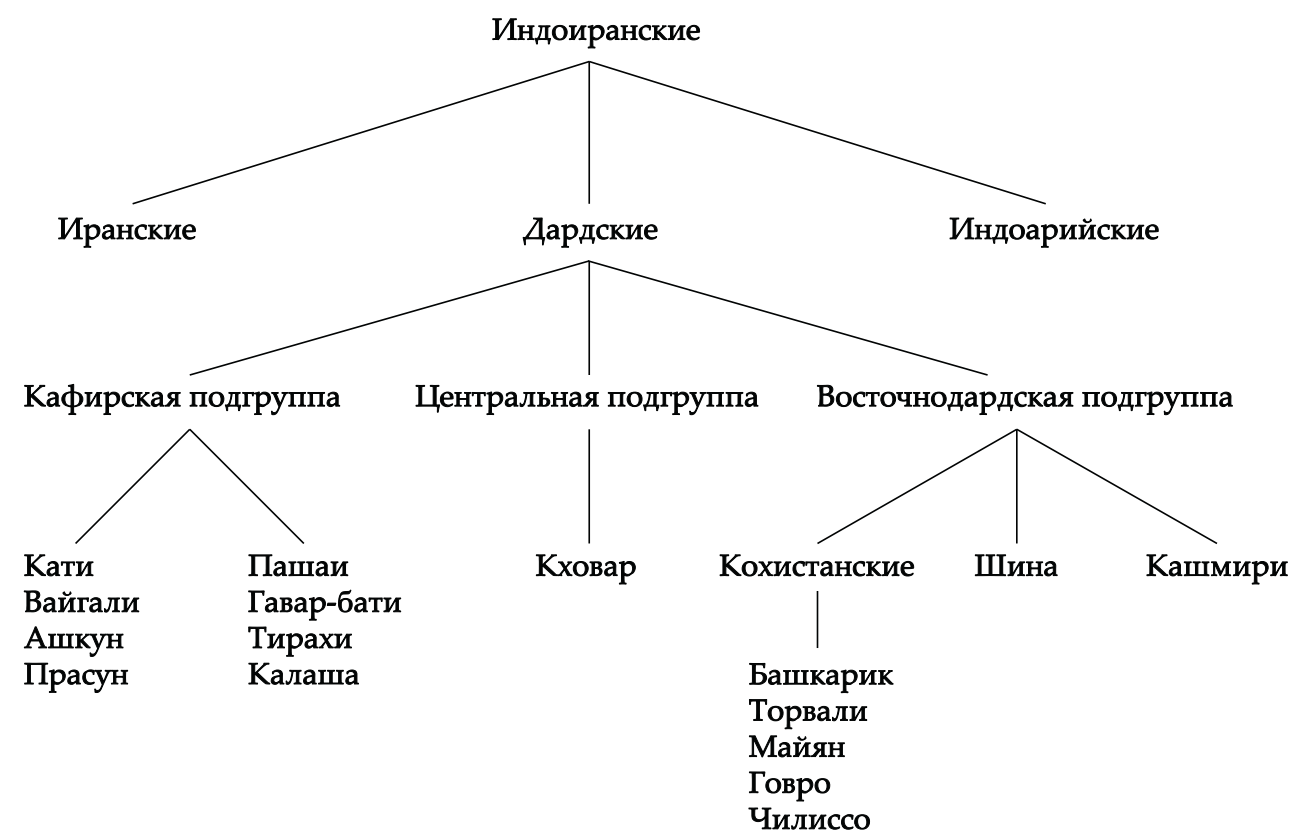

Рис. 1. Классификация языков дардской группы по Дж. Грирсону

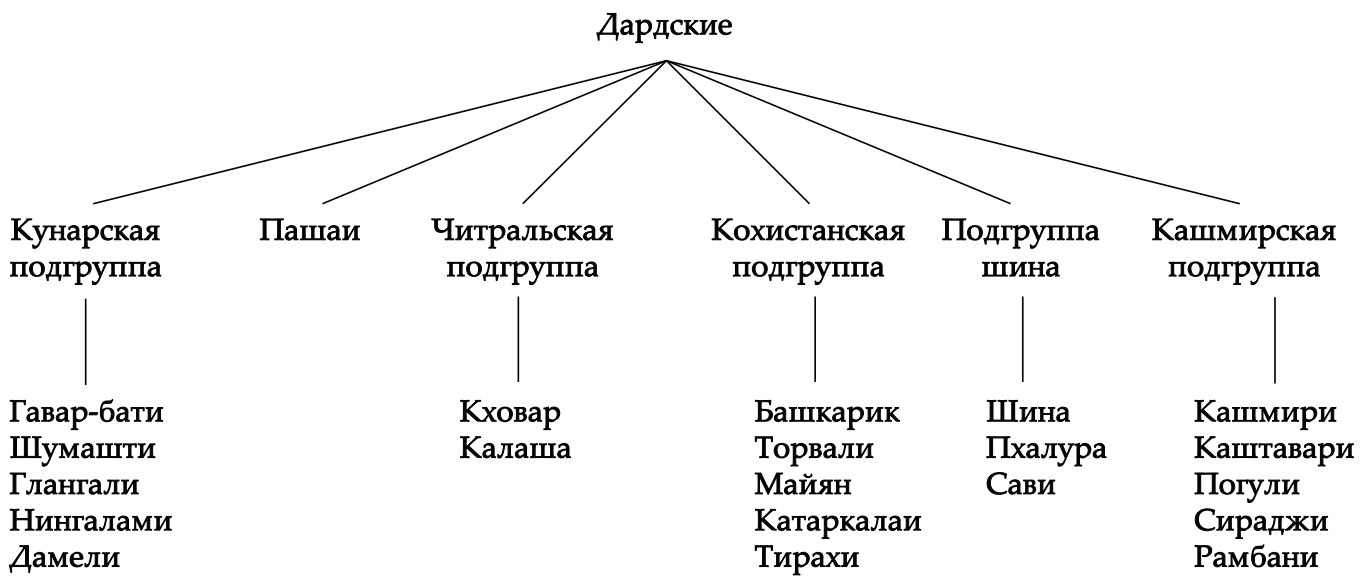

Рис. 2. Классификация языков дардской группы по Г. Моргенстьерне

Две приведенные здесь классификационные схемы различаются не только набором подгрупп ${ }^{4}$ но и их статусом. Убедительно показав генетическую самостоятельность нуристанских («кафирских» в более старой терминологии) языков, Г. Моргенстьерне отнес остальные языки, традиционно включавшиеся в дардскую группу, к индоарийским [Morgenstierne 1926; 1932; 1945; 1961; Buddruss 1977; Strand 1973; 2006; Edelman 1983;

${ }_{4}^{4}$ Определенные различия имеются также и в самом наборе дардских языков. Связаны они прежде всего с успехами полевых лингвистических исследований в регионе Восточного Гиндукуша в XX в., благодаря которым в научный обиход был введен материал неизвестных прежде языков. Так, языки пхалура, шумашти, нингалами и дамели были открыты и впервые описаны лично Г. Моргенстьерне [Morgenstierne 1941; 1942; 1945], язык вотапури (катаркалаи) и диалект сави - Г. Буддруссом [Buddruss 1960; 1967], язык глангали - А. Л. Грюнбергом [Грюнберг 1971]. 
Эдельман 1992]. При этом утверждалось, что дардские языки не разделяют ни одной общей отличительной черты, противопоставляющей их остальной индоарийской группе, то есть не образуют генетически единой подветви [Morgenstierne 1961]. Новейшие исследования показали, что данная точка зрения не может быть принята: дардская общность, несомненно, носит генетический характер, о чем свидетельствуют данные как исторической фонетики, так и лексикостатистики [Коган 2005]. Эти же данные не позволяют включать дардские языки в индоарийскую ветвь и заставляют относить их генетическое обособление ко времени распада индоиранского единства [Там же]. Таким образом, поднятый еще в работах Дж. Грирсона вопрос об этапах филиации дардской языковой общности вновь должен быть признан правомерным и заслуживающим тщательного рассмотрения.

Основная причина отсутствия консенсуса по поводу внутреннего членения дардской группы, по всей видимости, состоит в том, что все предлагавшиеся в прошлом классификационные схемы были в немалой степени интуитивными и не опирались на строгие сравнительно-исторические критерии. Следует сказать, что наличие некоторых постулируемых исследователями подгрупп, действительно, является интуитивно очевидным. Это относится, например, к кунарской подгруппе, включающей языки гавар-бати, шумашти, глангали и нингалами 5 . Число общих черт, разделяемых этими языками на разных уровнях, столь велико, что их тесное родство не вызывает сомнения. Данная ситуация, однако, является скорее исключением, нежели правилом. Поэтому следует признать, что классификационные схемы как Дж. Грирсона, так и Г. Моргенстьерне содержат немало непроверенных гипотез и ни в коем случае не должны приниматься безоговорочно.

К числу подобных гипотез, требующих проверки, относится предложенное Дж. Грирсоном выделение восточнодардской языковой общности. Вопрос о правомерности ее постулирования по-разному решался в приведенных выше классификациях, причем открытой полемики по данной проблеме по непонятным причинам не велось. Сам Дж. Грирсон основывался в значительной степени на наличии существенного количества

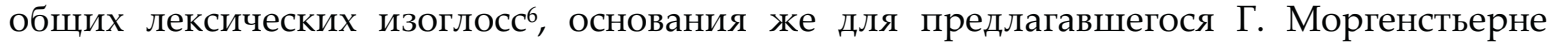
«разведения» кашмири, шина и кохистанских языков в 3 разные генетически не сближающиеся друг с другом подгруппы остаются неясными.

По-видимому, единственная попытка взглянуть на проблему с точки зрения исторической фонетики была сделана Г. Буддруссом. Признавая существование восточнодардской общности, он в работе, посвященной языку катаркалаи, называет 3 историкофонетические инновации, являющиеся, на его взгляд, восточнодардскими: переходы ${ }^{*} w>b,{ }^{*} s t>t(h)$ и ${ }^{*} s t>t(h)$ [Buddruss 1960, 71-72]. Следует сказать, что в полной мере точка зрения Г. Буддрусса неприемлема. Развитие * $w>b$ никоим образом не может считаться общевосточнодардским, поскольку не является характерным для кашмири, где древний w как правило сохраняется (ср. wāw 'ветер' при др.-инд. vāyu- 'воздух, ветер, божество ветра', авест. vaiiu- 'воздух, божество ветра'; wuh '20’ при др.-инд. viṃśati, авест. vīsaiti; wāy- ‘играть на музыкальном инструменте' при др.-инд. vādayati ‘заставляет звучать', па-

\footnotetext{
${ }^{5}$ Отнесение к кунарской подгруппе языка дамели представляется нам совершенно необоснованным. По целому ряду важных историко-фонетических характеристик этот язык сближается с нуристанскими языками и, вероятнее всего, должен включаться в число последних. Подробнее об этом см. [Коган 2007].

${ }^{6}$ Список таких изоглосс для кашмири и шина приводится в работе [Grierson 1919, 251-253]. Вызывает недоумение и сожаление тот факт, что этот список не стал в дальнейшем объектом серьезного обсуждения среди ученых.
} 
ли vādēti 'играет на музыкальном инструменте', осет. wadynz 'свирель'; woch 'теленок' при др.-инд. vatsa-, осет. (дигорский диал.) wæs то же; wačh 'грудь' при др.-инд. vakșas- то же, осет. wæxsk 'плечо'; wučh- 'видеть' при башк. bī̌ch-, тир. bīč- то же, др.-инд. vīkșate 'смотрит, видит') $)^{7}$. Не может претендовать на общевосточнодардский статус и развитие *șt > $t(h)$, поскольку старая группа șt (< общеиндоиран. *̌̌t) сохраняется или же изменяется иным образом в диалектах шина и в пхалура (ср. шина ãș (гильгитский диал.), așt (пуниальский диал.), пхал. așt ' 8 ' при др.-инд. așța( $(u)$, авест. ašta-; шина (кохистанский и гурезский диал.) mușțak, пхал. mușți 'кулак' при др.-инд. mușți- 'кулак, пригоршня', кл.-перс. mušt 'кулак'; пхал. drhiștu 'увиденный’ при др.-инд. drșta-, авест. dərəšta- то же). Переход *st $>t(h)$, по всей видимости, действительно, может считаться общим для всех восточнодардских языков. Характерен он прежде всего для древней интервокальной позиции (ср. кашм. athi, шина hat (гильгитский диал.), hatth (диал. палеси), сави hāth, пхал. hāt(h), май. hāth- (основа косвенных падежей), торв. hatth, катар. at(h) 'рука' при др.-инд. hasta-, авест. zasta-, др.-перс. dasta-; башк. othār 'род кожаной обуви' < *awastāra-, кашм. watharun 'циновка, коврик', шина bathāri 'постель' при др.-инд. upastaraña- 'покрытие', vistārayati 'pacстилает', авест. frastoronata- 'разостланный', ср.-перс. wistardan, кл.-перс. gustardan 'расстилать'; пхал. mātu, шина matu (гильгитский диал.), mattho (диал. палеси) 'мозг', катар. mat $(h)$ 'голова' при др.-инд. masta- 'голова', mastișka- 'мозг', mastrı̆han- то же, авест. mastarzyan, ормури mastory 'мозг', хот.-сак. māstai 'мозг, голова'; шина natho (диал. палеси), natho, natu (гильгитский диал.), торв. natkōl, май. nathūr, катар. nyet 'нос', кашм. nath-wāj 'кольцо в носу' при др.-инд. nasta- 'нос', nastaka- 'носовая перегородка', др.-иран. *nastī(> парачи nēšt) 'нос'). Примечательно при этом, что в дардских языках, не относимых Дж. Грирсоном к восточной подгруппе, интервокальная группа *st сохраняется (ср. тир. $\bar{a} s t$, паш. (даил. лауровани) hāst, диал. нирлами и гульбахари hōst, шум. aste-, нинг. wōst, г.-б., кал. hast, кховар host 'рука'; кал. ustrau 'постель'; г.-б. mastak, кал. $m(h) \bar{a} s t a$ 'мозг'; паш., кал. nāst, тир. nast 'нос', кховар nastuḷ 'носовая слизь').

Приведенные восточнодардские примеры требуют некоторых комментариев. Из трех встречающихся в них рефлексов интервокального ${ }^{*} t(t h$, th $и$ t) наиболее архаичным, по всей видимости, является первый. Ни в торвали, ни в диалектах шина, где этот рефлекс обнаруживается, не отмечено надежных случаев вторичной интервокальной или конечной геминации глухих. С другой стороны, в тех языках, где отражением рассматриваемой группы является одиночный смычный, геминированные согласные как таковые вообще не зафиксированы, что вполне может являться следствием упрощения более старых геминат. Рефлекс в виде непридыхательного $t$ отмечается в языках, где оппозиция по придыхательности, возможно, не характерна для некоторых позиций в слове (гильгитский диалект шина ${ }^{8}$ ), либо же может вообще не являться фонологичной (пха-

7 Примеры перехода * $w>b$ в кашмири весьма немногочисленны. Практически все они могут быть опознаны как индоарийские заимствования. В двух случаях появление нерегулярного $b$ может объясняться контаминацией с родственными словами в соседних дардских или индоарийских языках: bad- 'расти, увеличиваться' при др.-инд. vardhate, авест. varadaitī 'растет', пхал. bad-, хинди barh-, зап. пах. (диал. котгархи) bodh-, borhh-, догри badh- 'расти’; beh- 'садиться, сидеть' при др.-инд. upa-viśati ‘садится', авест. vīsantē ‘(они) занимают места', торв., май. $b(h) a y-$ - шина, bay-, пхал. bheš-, говро biš-, хинди, пандж. baițh-, лахнда bēh-, зап. пах. beś- (диал. котгархи), biś- (диал. бхадарвахи и бхалеси), baih- (диал. чамеали) 'садиться, сидеть').

${ }^{8}$ Ср., например, сосуществование двух фонетических вариантов слова со значением «лицо» - тик и mukh с историческим придыхательным (<*mukha-, ср. др.-инд. mukha-, общеиран. *muха- > пушту тәх 'лицо'). Примечательно также наличие приведенных выше обозначений носа паtho и паtи. Первое из них отмечено Д. А. Р. Лоримером, второе - Т. Г. Бейли. Наличие разнобоя в записях двух исследователей, вероятно, объясняется неустойчивостью придыхания в позиции перед конечным кратким гласным. 
лура, катаркалаи)9 . В одном случае (торв. natkōl 'нос') непридыхательный выступает перед последующим смычным, то есть в позиции, где артикуляция аспираты чрезвычайно затруднительна. Таким образом, во всех случаях $t<{ }^{*} s t$ непридыхательный мог развиться из более раннего придыхательного.

В кашмири и пхалура группа st обнаруживается в неизменном виде в названиях ноca: кашм. nast, пхал. nāst. Данный факт, скорее всего, как-то связан с наличием в обоих языках дублетных форм, продолжающих древнюю основу без $t$ (кашм. nas, пхал. nās < *nas-, ср. др.-инд. nas- 'нос'). Варианты с группой st могут являться результатом контаминации рефлексов древних основ *nas- и *nasta-10. Таким образом, конечный кластер в них, возможно, вторичен, и нет никаких весомых оснований считать эти варианты более архаичными, чем таковые с одиночным $s$.

Все вышесказанное дает нам основания считать возможной реконструкцию геминаты *th в качестве рефлекса общедардского интервокального кластера *st в гипотетическом общевосточнодардском праязыке. Следует, однако, отметить, что наличие следов перехода *st > th во всех языках, традиционно относимых к восточнодардским, является достаточно слабым аргументом в пользу восточнодардского единства. Как известно, данный переход широко распространен в индоарийских языках, где отмечается уже в среднеиндийскую эпоху [Woolner 1917, 19]. Если учесть также, что вплоть до XIV-XVI в. дардский языковой ареал непосредственно граничил с индоарийским как раз в зоне распространения языков, включаемых в гипотетическую восточнодардскую общность ${ }^{11}$, нельзя не признать, что рассматриваемая историко-фонетическая изоглосса может иметь ареальный, а не генетический характер.

Интересно отметить, что аналогичные проблемы встают и при изучении лексических изоглосс. Так, во всех восточнодардских языках имеются этимологически родственные глаголы со значением «есть, кушать» и «сидеть», не характерные для большинства прочих языков дардской группы: катар., башк., торв., май. khā-, пхал. $k h \bar{u}-$, шина $k h o-$, кашм. khe- 'есть, кушать' (< *khāda-, ср. др.-инд. khädati 'жует, ест', кл.-перс. xāyīdan 'жевать,

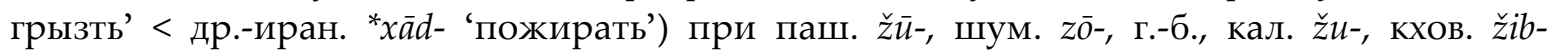
(< yaw-, ср. вах. уа̄w- 'есть, кушать'); башк. bäy-, торв., май. b(h)ay-, шина, катар. bay-, пхал. bheš-, кашм. beh- говро biš- 'садиться, сидеть' (< *wiś-/*waiś-, ср. авест. vīsantē '(они) занимают места', др.-инд. upaviśati 'садится', upavișta- 'сидящий') при паш. nё-, кхов. пǐ̌-, кал. nis- 'садиться, сидеть', г.-б. niši, шум. nisī ‘сидящий’ (<*ni-šad-, ср. др.-инд. nișīdati, авест. nišhiSaiti 'садится'). При этом, однако, восточнодардские глаголы имеют семантически тождественные соответствия в индоарийских языках: хинди, пандж., лахнда, гудж., мар., ория, бенг., асс., неп., кумаони, зап. пах. $k h \bar{a}-$, цыг. $x a-$, синдхи khi-, синг. $k a-$ 'есть, кушать'; хинди, пандж. baith-, лахнда bēh-, синдхи veh-, гудж. bes-, мар. bas-, ория baïth-, бенг. boš-, acc. boh-, зап. пах. (диал. котгархи) beś-, цыг. beš- 'сидеть, садиться'. Показательно также наличие этимологических параллелей в дардских языках, традиционно не причисляе-

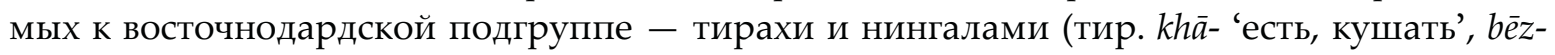
'сидеть, садиться', нинг. хиу- 'есть, кушать'). Язык тирахи обнаруживает некоторые общие

\footnotetext{
9 Об этом см. [Morgenstierne 1941, 11; Buddruss 1960, 17].

${ }^{10}$ Как указывалось выше, регулярное отражение основы *nasta- отмечено в кашмирском композите nath-wāj ‘кольцо в носу’.

${ }_{11}$ В настоящее время дардский и индоарийский ареалы непосредственно не соприкасаются нигде за исключением территории индийского штата Джамму и Кашмир. Связано это с миграциями пуштунов в XIV-XVI вв. Диалекты языка пушту сыграли роль клина, отрезавшего носителей дардских языков от индоязычного населения северо-западного Индостана.
} 
изоглоссы с восточнодардскими языками ${ }^{12}$, однако не обнаруживает перехода интервокального *st $>$ th. Нингалами же, вне всякого сомнения, относится к кунарской подгруппе.

Таким образом, следует признать, что среди рассмотренных здесь историкофонетических и лексических изоглосс ни одну нельзя с полным основанием считать классифицирующей для восточнодардских языков. Анализ этих изоглосс не дает ясного ответа на вопрос о восточнодардском генетическом единстве. Скорее, он позволяет поставить этот вопрос в более четкой и конкретной формулировке: являются ли выделяемые в классификации Дж. Грирсона восточнодардские языки генетической общностью или же они представляют собой ареальное объединение дардских языков разных подгрупп, вторично сблизившихся не в последнюю очередь благодаря совместным контактам с индоарийскими языками?

Существенно прояснить данную ситуацию могло бы, на наш взгляд, использование метода лексикостатистики. В нашей работе «Дардские языки. Генетическая характеристика» [Коган 2005] этот метод уже применялся для определения места дардских языков внутри арийской языковой общности. Там же была предложена методика выявления как несомненных, так и вероятных индоарийских заимствований в стословных списках дардских языков [Коган 2005, 168-172]. Дексикостатистические подсчеты, дополненные данной методикой, могли бы дать весьма важные и показательные результаты и, несомненно, позволили бы вплотную приблизиться к решению проблемы восточнодардской языковой общности. К счастью, в последние годы объем доступного материала по восточнодардским языкам существенно увеличился. Вышел в свет крупный словарь языка майян [Zoller 2005], был составлен двуязычный электронный торвали-урду словарь [Online Torwali Dictionary 2011], благодаря недавней публикации Р. А. Шмидт и В. К. Кауля в журнале Acta Orientalia [Schmidt, Kaul 2008] в научный обиход был введен весьма значительный объем неизвестной ранее лексики пяти диалектов шина (кохистанского, гурезского, асторского, драсского и брокската) ${ }^{13}$. Все это сделало возможным создание достаточно детальной (особенно в сравнении более ранним временем ${ }^{14}$ ) классификации дардских языков, опирающейся на лексикостатистические данные.

Ниже делается попытка построения такой классификации для 16 дардских языков и диалектов. Основой использованной нами базы данных является более ранняя база, составленная при работе над монографией [Коган 2005]. Эта база, из которой нами взята основная часть этимологий, была дополнена списками по диалектам шина и языкам майян, торвали, говро и башкарик ${ }^{15}$. Относительно некоторых из этих добавленных списков необходимо сделать ряд замечаний. В стословном списке брокскат имеется заметное количество слов с неустановленной этимологией. Для некоторых из них, как представляется, можно предложить приемлемые этимологические решения. Прилагатель-

12 О них см. [Grierson 1927, 266]. Возможно именно на наличии таких изоглосс основывался Г. Моргенстьерне, включая тирахи в кохистанскую подгруппу.

13 До выхода этой статьи единственным диалектом шина, по которому в распоряжении исследователей имелся более или менее значительный (в частности, достаточный для составления стословного списка) корпус лексики, был гильгитский.

${ }^{14}$ Еще совсем недавно ситуация была совершенно иной. Так, в нашей недавней монографии [Коган 2005] привлечь для лексикостатистических подсчетов оказалось возможным материал лишь семи дардских языков (в том числе трех восточнодардских - кашмири, шина и пхалура). При таком количестве списков удалось с достаточной точностью установить генетические отношения языков дардской группы с прочими арийскими, однако внутреннее членение дардской языковой общности осталось во многом неясным.

${ }^{15}$ Кроме того, новые материалы, появившиеся в нашем распоряжении в течение последних лет, позволили внести отдельные коррективы в стословные списки кашмири и пхалура. 
ное bōno 'большой', вероятно, связано с семантически тождественными словами в других диалектах шина (гильгитск. boru, гурезск. baru, драсск., астор., кохист. baṛ) и восходит к общедардскому корню *ward- 'расти' (< общеарийск. *wardh-, ср. др.-инд. vardh-, авест. varad- 'расти') ${ }^{16}$. Появление интервокального $n$ вместо ожидаемого $r$ в брокскат можно объяснить аналогией с прилагательным sеno 'маленький'. Первый компонент сложного

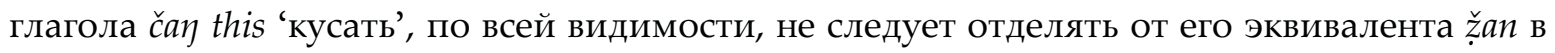
гильгитском диалекте и jan в асторском и драсском диалектах шина ${ }^{17}$. Начальный $\check{,}$ возможно, возник по аналогии с синонимичным глагольным корнем с̌ар-, утраченном в брокскат, но имеющемся в целом ряде диалектов шина (гильгитск. с̌apoiki, гурезск. с̌аруо̄nu, кохист. с̌аро̄n 'кусать'), а также в некоторых других дардских языках (ср. май., говро сар-, г.-б. сер- 'кусать', кашм. сор 'укус'). Брокскат bēldaך 'ночь' представляется неотделимым от семантически близких слов в ряде других дардских языков: паш. wyāl, шум. wyel, г.-б. yel 'ночь', май. bilāl 'вечер, сумерки; вчера, прошлой ночью', башк. žāl, торв. byäl, шина (гильгитский диал.) bălā, (гурезский, кохистанский диал.) byālĕ 'вчера'. Название песка в брокскат (sīri), вероятнее всего продолжает общедардскую основу *sika-/*śika'песок'18. Непосредственный прототип для данного слова можно реконструировать как * sika-r-ī, где $r$ - распространенный в арийских языках словообразовательный суффикс ${ }^{19}$, а $\bar{\imath}$ - окончание женского рода. Выпадение интервокального глухого смычного для брокскат, по-видимому, регулярно (ср. šyo '100' при др.-инд. śatam, авест. satəm).

Заимствования в добавленных столовных списках чаще всего легко распознаваемы. Тибетские элементы в списке брокскат были выявлены в работе [Schmidt, Kaul 2008]. Индоарийские заимствования в торвали, майян, говро и башкарик ${ }^{20}$ выделялись по двум критериям, использованным в нашей монографии [Коган 2005], а именно историкофонетическому и лингвогеографическому (наличие у данного слова этимологических параллелей в дардских языках, не подверженных индоарийскому влиянию). Следы индоарийского историко-фонетического развития, причем затушеванные поздними процессами, обнаруживаются в названии ночи: май. rāl, говро rāu (ср. др.-инд. rātrī, хинди, пандж., лахнда $r \bar{a} t)$. В обоих языках конечный элемент возник из более раннего смычного $t$ (ср. май. šal, говро šav '100' < ‘śatam). При этом древняя группа tr отражается в них в ви-

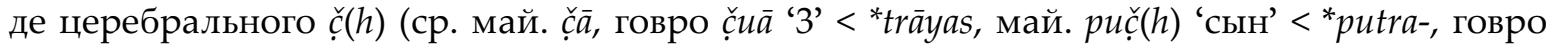
pōç 'внук' < * pautra-). Наиболее вероятной причиной подобного разнобоя рефлексов является заимствование в майян и говро индийской формы с конечным $t$ до того, как прошли характерные для этих языков переходы ${ }^{*} t>l$ и ${ }^{*} t>u, v$. Следует сказать, что индоарийское слово для ночи было заимствовано также в кашмири, башкарик, шина, пхалура и калаша [Коган 2005, 168-169].

По лингвогеографическому критерию нами были выделены следующие вероятные индоарийские заимствования: май. har, говро $h \bar{a} r$, торв. $h \bar{a} r$, башк. had 'кость' (ср. пракр.

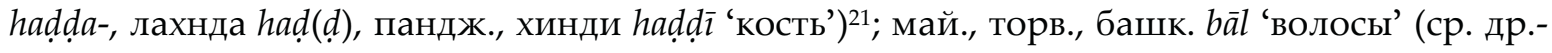

${ }^{16}$ Об этимологии прилагательного ‘большой’ в шина и кашмири см. [Коган 2005, 165-166].

${ }_{17}^{17}$ Во всех перечисленных диалектах это слово функционирует как часть сложноименного глагола со значением 'кусать’: гильгитск. žan thoiki, асторск. jan thōnu, драсск. jan thyōno.

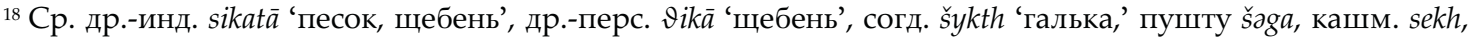
шина, пхал., май., торв., говро sigal, г.-б. sīü, паш. sēo, кхов. šuүur, кал. šigou 'песок'.

${ }^{19} \mathrm{C}$ этим суффиксом ср., напр., др.-инд. sü-ka-r-a- 'свинья' (перс. $\chi \bar{u} g<{ }^{*} h \bar{u}-k a-$ то же); индоарийск. *padara- 'нога' > хинди, пандж. pair.

${ }^{20}$ Об индоарийском влиянии на кохистанские языки см. [Grierson 1969, 6; 1929, 3; 1919, 3, 507].

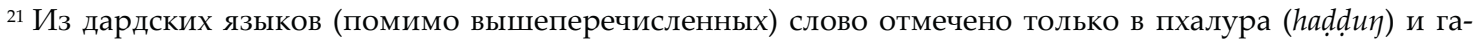
вар-бати (had). Оба языка, так же как и языки кохистанской подгруппы, были подвержены индоарийскому 
инд. vāla- 'волос', лахнда, пандж. vāl, хинди $b \bar{a} l$, зап. пах. (чамеали) $b \bar{a} l$ 'волос(ы)'222; май., говро pīl, г.-б. phiala 'желтый’ (ср. др.-инд. pittala-, пракр. pīala-, хинди, пандж., лахнда pīlā, синдхи piaro, бенг. pilā, гудж. pīlũ 'желтый’)23; май. gharĩ 'женщина' (ср. пали gharaṇi-,

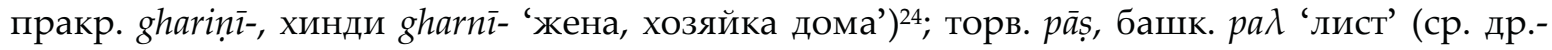
инд. pattra-, лахнда pattar, зап. пах. (бхалеси) pațl с регулярным $t ! l<t r$, пандж., хинди pattā 'лист').

В стословном списке торвали имеется персидское заимствование, претерпевшее значительные фонетические изменения и в силу этого не столь очевидное. Это название печени jogō (ср. кл.-перс. jigar 'печень' < др.-иран. “yakar-). Наличие нехарактерного для торвали перехода у > ј в начальном положении не позволяет считать данную лексему исконной. Показательно также, что в близкородственном торвали языке башкарик исконное название печени (уӓ̄n) продолжает иную древнюю основу - основу косвенных падежей *yakn-. С другой стороны, развитие современной формы jogō из более ранней jigar в результате некоторых недавних историко-фонетических процессов представляется вполне возможным. Падение интервокального и конечного поствокального $r$ (а также церебрального $?$ ) является характерной особенностью языка торвали ${ }^{25}$. Обнаруживается оно как в исконной лексике, так и в части арабских и персидских заимствований ${ }^{26}$ (ср. hušā 'умный' < кл.-перс. hušyār то же; tī̄ 'готовый' < кл.-перс. taìyār то же < араб.). Известны также примеры развития конечного долгого $\bar{o}$ из краткого $a$, возникшего после падения $r$ или r: $b o g(h)$ o 'овцы' при башк. bakar 'козы', тир. bakara 'баран' (вероятно, индоарийское заимствование, ср. хинди $b a k r \bar{a}$, пандж., лахнда $b a k k r \bar{a}$, 'козел’, цыг. bakro 'баран', др.-инд.

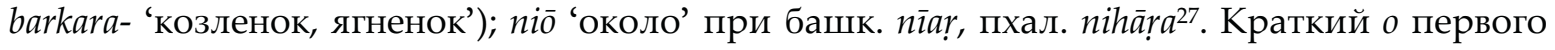
слога в торв. jogō, скорее всего, возник в результате регрессивной ассимиляции гласных.

Полные стословные списки, использованные в работе, приводятся в Приложении с указанием общих этимологий и выявленных заимствований.

Для проведения лексикостатистического анализа была составлена обновленная стословная база, включающая лексический материал по 16 дардским языкам и диалектам. Первичная обработка данных проводилась в системе Starling: при этом для каждой пары идиомов подсчитывалась доля общей лексики в их основных списках без учета заимствований. Расчетные значения долей совпадений (при $1=100 \%$ ) приведены в соответствующих ячейках табл. 1.

Полученные доли совпадения стословных списков являются исходными данными для дальнейшего лексикостатистического анализа дардских языков.

Первый (подготовительный) этап анализа состоит в проверке исходных данных на внутреннюю согласованность. Смысл и содержание данной процедуры поясним на при-

влиянию, а также сильному влиянию пушту, где также имеется данное обозначение кости (had, hadukay). Заимствование, таким образом, могло проникнуть как непосредственно из новоиндийского источника, так и через посредство пушту.

${ }^{22}$ Слово отмечено только в кохистанских языках и пхалура (bola).

${ }^{23}$ При широком распространении в индоарийских языках слово отсутствует в близкородственных кохистанских.

${ }^{24}$ В значении 'женщина' ни в одном другом дардском языке слово не отмечено. В значении 'жена' имеется в кашмирском диалекте каштавари (gariñ). С неисконным происхождением слова в майян, вероятно, связано наличие звонкого придыхательного.

${ }^{25}$ О ней см. [Grierson 1929, 15].

26 Часть таких заимствований, возможно, проникла в торвали через посредство пушту.

${ }_{27}^{27}$ Долгий $\bar{a}$ в пхалура из более раннего краткого $a$. Слово, возможно, связано с др.-инд. nikatam 'рядом, около'. 
Табл. 1. Доли совпадения основных списков дардских языков

\begin{tabular}{l|l|c|c|c|c|c|c|c|c|c|c|c|c|c|c|c|c}
\hline № & Языки & $\mathbf{1}$ & $\mathbf{2}$ & $\mathbf{3}$ & $\mathbf{4}$ & $\mathbf{5}$ & $\mathbf{6}$ & $\mathbf{7}$ & $\mathbf{8}$ & $\mathbf{9}$ & $\mathbf{1 0}$ & $\mathbf{1 1}$ & $\mathbf{1 2}$ & $\mathbf{1 3}$ & $\mathbf{1 4}$ & $\mathbf{1 5}$ & $\mathbf{1 6}$ \\
\hline $\mathbf{1}$ & KSM & 1 & 0.63 & 0.64 & 0.62 & 0.57 & 0.52 & 0.45 & 0.54 & 0.68 & 0.67 & 0.61 & 0.6 & 0.63 & 0.62 & 0.67 & 0.68 \\
\hline $\mathbf{2}$ & GLT & 0.63 & 1 & 0.78 & 0.72 & 0.61 & 0.53 & 0.48 & 0.6 & 0.73 & 0.71 & 0.84 & 0.9 & 0.92 & 0.9 & 0.71 & 0.71 \\
\hline $\mathbf{3}$ & BRK & 0.64 & 0.78 & 1 & 0.69 & 0.6 & 0.52 & 0.46 & 0.6 & 0.68 & 0.67 & 0.77 & 0.76 & 0.76 & 0.75 & 0.69 & 0.65 \\
\hline $\mathbf{4}$ & PHL & 0.62 & 0.72 & 0.69 & 1 & 0.67 & 0.57 & 0.49 & 0.63 & 0.78 & 0.81 & 0.68 & 0.66 & 0.67 & 0.69 & 0.78 & 0.82 \\
\hline $\mathbf{5}$ & GAW & 0.57 & 0.61 & 0.6 & 0.67 & 1 & 0.66 & 0.52 & 0.67 & 0.64 & 0.66 & 0.59 & 0.56 & 0.6 & 0.64 & 0.67 & 0.63 \\
\hline $\mathbf{6}$ & PSH & 0.52 & 0.53 & 0.52 & 0.57 & 0.66 & 1 & 0.56 & 0.65 & 0.55 & 0.57 & 0.49 & 0.49 & 0.51 & 0.53 & 0.57 & 0.58 \\
\hline $\mathbf{7}$ & KHO & 0.45 & 0.48 & 0.46 & 0.49 & 0.52 & 0.56 & 1 & 0.61 & 0.47 & 0.48 & 0.44 & 0.43 & 0.45 & 0.48 & 0.52 & 0.52 \\
\hline $\mathbf{8}$ & KAL & 0.54 & 0.6 & 0.6 & 0.63 & 0.67 & 0.65 & 0.61 & 1 & 0.63 & 0.64 & 0.54 & 0.52 & 0.55 & 0.61 & 0.63 & 0.69 \\
\hline $\mathbf{9}$ & MAY & 0.68 & 0.73 & 0.68 & 0.78 & 0.64 & 0.55 & 0.47 & 0.63 & 1 & 0.85 & 0.68 & 0.69 & 0.74 & 0.78 & 0.87 & 0.81 \\
\hline $\mathbf{1 0}$ & TOR & 0.67 & 0.71 & 0.67 & 0.81 & 0.66 & 0.57 & 0.48 & 0.64 & 0.85 & 1 & 0.7 & 0.65 & 0.71 & 0.74 & 0.82 & 0.89 \\
\hline $\mathbf{1 1}$ & DRS & 0.61 & 0.84 & 0.77 & 0.68 & 0.59 & 0.49 & 0.44 & 0.54 & 0.68 & 0.7 & 1 & 0.87 & 0.89 & 0.8 & 0.7 & 0.67 \\
\hline $\mathbf{1 2}$ & AST & 0.6 & 0.9 & 0.76 & 0.66 & 0.56 & 0.49 & 0.43 & 0.52 & 0.69 & 0.65 & 0.87 & 1 & 0.94 & 0.85 & 0.66 & 0.65 \\
\hline $\mathbf{1 3}$ & GUR & 0.63 & 0.92 & 0.76 & 0.67 & 0.6 & 0.51 & 0.45 & 0.55 & 0.74 & 0.71 & 0.89 & 0.94 & 1 & 0.86 & 0.71 & 0.68 \\
\hline $\mathbf{1 4}$ & KOH & 0.62 & 0.9 & 0.75 & 0.69 & 0.64 & 0.53 & 0.48 & 0.61 & 0.78 & 0.74 & 0.8 & 0.85 & 0.86 & 1 & 0.76 & 0.74 \\
\hline $\mathbf{1 5}$ & GOW & 0.67 & 0.71 & 0.69 & 0.78 & 0.67 & 0.57 & 0.52 & 0.63 & 0.87 & 0.82 & 0.7 & 0.66 & 0.71 & 0.76 & 1 & 0.79 \\
\hline $\mathbf{1 6}$ & BSK & 0.68 & 0.71 & 0.65 & 0.82 & 0.63 & 0.58 & 0.52 & 0.69 & 0.81 & 0.89 & 0.67 & 0.65 & 0.68 & 0.74 & 0.79 & 1 \\
\hline
\end{tabular}

О бозн ачения:

KSM - кашмири
GLT - гильгитский диалект шина
BRK - брокскат
PHL - пхалура
GAW - гавар-бати
PSH - пашаи
KHO - кховар
KAL - калаша

KSM - кашмири

MAY - майян

TOR - торвали

DRS - драсский диалект шина

AST - асторский диалект шина

GUR - гурезский диалект шина

$\mathrm{KOH} \mathrm{-} \mathrm{кохистанский} \mathrm{диалект} \mathrm{шина}$

GOW - говро

BSK - башкарик

мере трех диалектов шина: драсского (DRS), асторского (AST) и гурезского (GUR). Доли совпадения их основных списков приведены в табл. 1: $\mathrm{N}_{\mathrm{DRS}-\mathrm{AST}}=0,87 ; \mathrm{N}_{\mathrm{AST}-\mathrm{GUR}}=0,94$; $\mathrm{N}_{\text {DRS-GUR }}=0,89$. Для наглядности воспользуемся рис. За, на котором значения $\mathrm{N}$ указаны рядом с дугами, соединяющими соответствующие языки.

Согласно этимологическим оценкам, расхождение между основными списками идиомов DRS и AST составляет 13 значений ${ }^{28}(1-0,87=0,13)$, а между AST и GUR - 6 значений $(1-0,94=0,06)$.

Если мы допустим, что ни одно из 6-ти значений, отличающих стословные списки диалектов AST и GUR, не совпадает ни с одним из 13-ти значений, отличающихся в основных списках DRS и AST, то число несовпадающих слов в основных списках DRS и GUR будет равно 19: 6+13=19.

28 Термин «значение» использован здесь условно, так как в основных списках всех трех диалектов присутствуют заимствования, и в действительности доля совпадений вычислена не от 100, а от меньшего количества слов. Таким образом, соотношение 0,01=1 слово является в этом случае только приблизительным. 


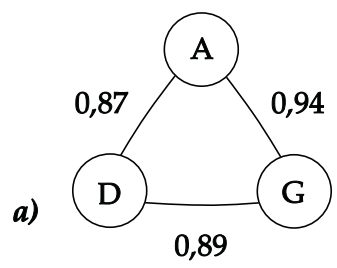

б)

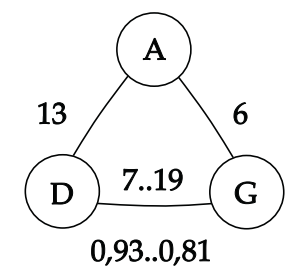

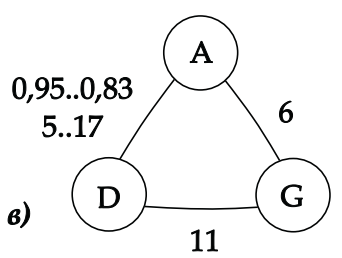

2)

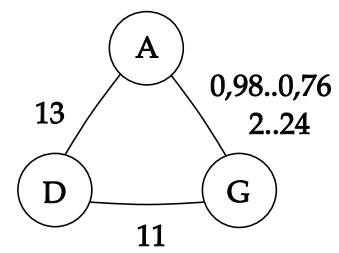

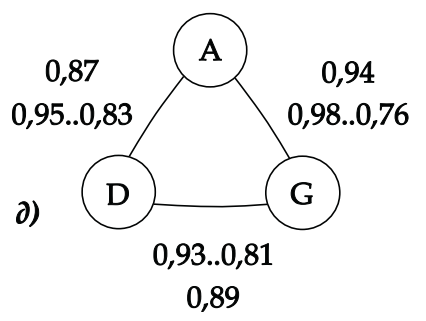

Рис. 3. Иллюстрация согласованности долей совпадений между основными списками драсского (D), асторского (А) и гурезского (G).

Если допустить, что все 6 значений, различающие идиомы AST и GUR входят в 13 значений, которыми отличаются DRS и AST, то расхождение между списками DRS и GUR составит 7 слов: $13-6=7$.

Таким образом, число расхождений между стословными списками DRS и GUR может лежать в пределах от 7 до 19 слов, что соответствует $\mathrm{N}_{\mathrm{DRS}-\mathrm{GUR}}=0,93 \ldots . .0,81$ (рис. 3б). Очевидно, что значение $\mathrm{N}_{\mathrm{DRS}-\mathrm{GUR}}=0,89$ (табл. 1) входит в этот интервал, то есть экспертная оценка для пары драсский-гурезский является согласованной по отношению к асторскому диалекту.

Аналогичные рассуждения, проведённые для пары DRS-AST по отношению к GUR (рис. 1в), а также пары AST-GUR по отношению к DRS (рис. 1г), показывают, что оценки N для любых двух диалектов согласованы относительно третьего. В этом легко убедиться, сравнив рис. 1а с рис. 1д, на котором сведены результаты проверки для всех трёх пар. Таким образом, чтобы сделать вывод о согласованности внутри некоторой триады языков достаточно установить согласованность любых двух из них относительно третьего. В том случае, если это невозможно, триаду следует считать несогласованной.

Вслед за С. А. Старостиным и С. А. Бурлак назовем вышеизложенный способ проверки исходных данных «критерием транзитивности» ${ }^{29}$. Формально условие транзитивности для трех произвольных языков А, В и С можно записать следующим образом:

$$
\mathrm{N}_{\mathrm{AB}}+\mathrm{N}_{\mathrm{BC}}-1 \leq \mathrm{N}_{\mathrm{AC}} \leq 1-\left|\mathrm{N}_{\mathrm{AB}}-\mathrm{N}_{\mathrm{BC}}\right|
$$

Для рассмотренного выше примера с драсским, асторским и гурезским диалектами выражение примет вид:

$$
\begin{gathered}
\left(\mathrm{N}_{\mathrm{DRS}-\mathrm{AST}}=0,87 ; \mathrm{N}_{\mathrm{AST}-\mathrm{GUR}}=0,94 ; \mathrm{N}_{\mathrm{DRS}-\mathrm{GUR}}=0,89\right) \\
\mathrm{N}_{\text {DRS-AST }}+\mathrm{N}_{\text {AST-GUR }}-1 \leq \mathrm{N}_{\text {DRS-GUR }} \leq 1-\left|\mathrm{N}_{\text {DRS-AST }}-\mathrm{N}_{\text {AST-GUR }}\right| \\
0,87+0,94-1 \leq 0,89 \leq 1-|0,87-0,94| \\
0,81 \leq 0,89 \leq 0,93
\end{gathered}
$$

29 Данный критерий предложен в работе [Бурлак, Старостин 2005, 103] и основан на схожем способе рассуждений. 
Очевидно, полученное неравенство является верным, что указывает на выполнение условия транзитивности для данной триады языков.

В группе из 16 языков общее количество триад, подлежащих проверке на согласованность, равно 560 (число сочетаний из 16 по 3):

$$
C_{16}^{3}=\frac{16 !}{(16-3) ! 3 !}=560
$$

Проведенные расчеты показали, что все 560 триад, образованные значениями долей совпадений из табл. 1, удовлетворяют условию транзитивности.

Несмотря на положительный результат проверки, следует подчеркнуть, что критерий транзитивности является необходимым, но не достаточныл условием достоверности исходных данных (табл. 1). Справедливость данного критерия для некоторого набора языков не гарантирует отсутствие заимствований или неверно установленных этимологий при сравнении стословных списков. В то же время невыполнение условия транзитивности с однозначностью свидетельствует о наличии подобных ошибок ${ }^{30}$ и, как следствие, ненадежности результатов первичного этимологического анализа.

Убедившись в согласованности исходных лексикостатистических данных, перейдем к составлению генеалогической классификации дардских языков. Для этого воспользуемся вначале стандартным методом Starling, а затем альтернативной методикой наименьших средних отклонений. Привлечение двух различных подходов позволит провести сравнительный анализ полученных деревьев, установить наиболее вероятный вид итоговой классификации, а также оценить статистическую надежность её узлов.

Процедура построения генетического дерева в системе Starling представляет собой особую разновидность метода «ближайших соседей» и подробно описана в работе [Бурлак, Старостин 2005, 162-167]. В основе метода лежит следующее эмпирическое утверждение: чем больше общей лексики в основных списках сравниваемых языков, тем позже эти языки разделились. При этом идиомы с наибольшим значением совпадений, очевидно, являются ближайшими родственниками («соседями») и, следовательно, должны быть объединены в общий узел генеалогического дерева. В табл. 1 наиболее тесное родство демонстрируют асторский и гурезский диалект шина с долей совпадения $\mathrm{N}_{\mathrm{AST}-\mathrm{GUR}}=0,94$. B peзультате идиомы AST и GUR сводятся в один узел (AST+GUR), а соответствующие строки и столбцы табл. 1 (12 и 13) объединяются с усреднением их значений ${ }^{31}$ (см. табл. 2, 3).

Аналогичным образом процедура поиска и объединения «ближайших соседей» повторяется для таблицы из 15-ти языков, затем - для 14 и так далее, пока все рассматриваемые идиомы не будут сведены к единому «праязыку» - корню дерева. Полученная генетическая классификация дардских языков представлена на рис. 4.

Несмотря на простоту в использовании и широкое распространение, метод «ближайших соседей» обладает рядом существенных недостатков. На главный из них указывает в своей работе С. А. Старостин: «(... сравнивая ОС [основные списки. - М. В., А. К.] двух языков, мы получаем только один результат, а для повышения надёжности выводов

\footnotetext{
30 При этом мы не рассматриваем проблему составления стословных списков, качество которых в первую очередь определяет точность конечного результата. Подробному обсуждению этой основополагающей проблемы лексикостатистики посвящена статья [Kassian et al. 2010].

31 Здесь изложение методики приводится для общего случая - когда доля совпадений между объединяемыми идиомами составляет менее 70\%. Для языков с долей совпадения более 70\% (в последних версиях Starling - 75\%) при объединении используются не средние, а наименьшие значения [Бурлак, Старостин 2005, 164].
} 
Таблица 2. Фрагмент табл. 1 с наибольшим значением N, соответствующим «ближайшим соседям» - диалектам AST и GUR

\begin{tabular}{c|l|c|c|c|c|c|c|c|c|c|c|c|c|c|c|c|c}
\hline № & Язык & $\begin{array}{c}\mathbf{1} \\
\text { KSM }\end{array}$ & $\begin{array}{c}\mathbf{2} \\
\text { GLT }\end{array}$ & $\begin{array}{c}\mathbf{3} \\
\text { BRK }\end{array}$ & $\begin{array}{c}\mathbf{4} \\
\text { PHL }\end{array}$ & $\begin{array}{c}\mathbf{5} \\
\text { GAW }\end{array}$ & $\begin{array}{c}\mathbf{6} \\
\text { PSH }\end{array}$ & $\begin{array}{c}\mathbf{7} \\
\text { KHO }\end{array}$ & $\begin{array}{c}\mathbf{8} \\
\text { KAL }\end{array}$ & $\begin{array}{c}\mathbf{9} \\
\text { MAY }\end{array}$ & $\begin{array}{c}\mathbf{1 0} \\
\text { TOR }\end{array}$ & $\begin{array}{c}\mathbf{1 1} \\
\text { DRS }\end{array}$ & $\begin{array}{c}\mathbf{1 2} \\
\text { AST }\end{array}$ & $\begin{array}{c}\mathbf{1 3} \\
\text { GUR }\end{array}$ & $\begin{array}{c}\mathbf{1 4} \\
\text { KOH }\end{array}$ & $\begin{array}{c}\mathbf{1 5} \\
\text { GOW }\end{array}$ & $\begin{array}{c}\mathbf{1 6} \\
\text { BSK }\end{array}$ \\
\hline $\mathbf{1 1}$ & DRS & 0.61 & 0.84 & 0.77 & 0.68 & 0.59 & 0.49 & 0.44 & 0.54 & 0.68 & 0.7 & 1 & 0.87 & 0.89 & 0.8 & 0.7 & 0.67 \\
\hline $\mathbf{1 2}$ & AST & 0.6 & 0.9 & 0.76 & 0.66 & 0.56 & 0.49 & 0.43 & 0.52 & 0.69 & 0.65 & 0.87 & 1 & 0.94 & 0.85 & 0.66 & 0.65 \\
\hline $\mathbf{1 3}$ & GUR & 0.63 & 0.92 & 0.76 & 0.67 & 0.6 & 0.51 & 0.45 & 0.55 & 0.74 & 0.71 & 0.89 & 0.94 & 1 & 0.86 & 0.71 & 0.68 \\
\hline $\mathbf{1 4}$ & KOH & 0.62 & 0.9 & 0.75 & 0.69 & 0.64 & 0.53 & 0.48 & 0.61 & 0.78 & 0.74 & 0.8 & 0.85 & 0.86 & 1 & 0.76 & 0.74 \\
\hline
\end{tabular}

Таблица 3. Фрагмент табл. 1 после объединения идимов AST и GUR в общий узел (соответствующие строки и столбцы объединены)

\begin{tabular}{l|l|c|c|c|c|c|c|c|c|c|c|c|c|c|c|c}
\hline \multirow{2}{*}{ № } & Язык & $\begin{array}{c}\mathbf{1} \\
\text { KSM }\end{array}$ & $\begin{array}{c}\mathbf{2} \\
\text { GLT }\end{array}$ & $\begin{array}{c}\mathbf{3} \\
\text { BRK }\end{array}$ & $\begin{array}{c}\mathbf{4} \\
\text { PHL }\end{array}$ & $\begin{array}{c}\mathbf{5} \\
\text { GAW }\end{array}$ & $\begin{array}{c}\mathbf{6} \\
\text { PSH }\end{array}$ & $\begin{array}{c}\mathbf{7} \\
\text { KHO }\end{array}$ & $\begin{array}{c}\mathbf{8} \\
\text { KAL }\end{array}$ & $\begin{array}{c}\mathbf{9} \\
\text { MAY }\end{array}$ & $\begin{array}{c}\mathbf{1 0} \\
\text { TOR }\end{array}$ & $\begin{array}{c}\mathbf{1 1} \\
\text { DRS }\end{array}$ & $\begin{array}{c}\mathbf{1 2} \\
\text { AST+GUR }\end{array}$ & $\begin{array}{c}\mathbf{1 3} \\
\text { KOH }\end{array}$ & $\begin{array}{c}\mathbf{1 4} \\
\text { GOW }\end{array}$ & $\begin{array}{c}\mathbf{1 5} \\
\text { BSK }\end{array}$ \\
\hline $\mathbf{1 1}$ & DRS & 0.61 & 0.84 & 0.77 & 0.68 & 0.59 & 0.49 & 0.44 & 0.54 & 0.68 & 0.7 & 1 & $\mathbf{0 . 8 8}$ & 0.8 & 0.7 & 0.67 \\
\hline $\mathbf{1 2}$ & AST+GUR & $\mathbf{0 . 6 1 5}$ & $\mathbf{0 . 9 1}$ & $\mathbf{0 . 7 6}$ & $\mathbf{0 . 6 6 5}$ & $\mathbf{0 . 5 8}$ & $\mathbf{0 . 5}$ & $\mathbf{0 . 4 4}$ & $\mathbf{0 . 5 3 5}$ & $\mathbf{0 . 7 1 5}$ & $\mathbf{0 . 6 8}$ & $\mathbf{0 . 8 8}$ & 1 & $\mathbf{0 . 8 5 5}$ & $\mathbf{0 . 6 8 5}$ & $\mathbf{0 . 6 6 5}$ \\
\hline $\mathbf{1 3}$ & КОH & 0.62 & 0.9 & 0.75 & 0.69 & 0.64 & 0.53 & 0.48 & 0.61 & 0.78 & 0.74 & 0.8 & $\mathbf{0 . 8 5 5}$ & 1 & 0.76 & 0.74 \\
\hline
\end{tabular}

хотелось бы иметь серию результатов (для которых можно было бы вычислить математическое ожидание и возможные пределы отклонений)» [Старостин 2007: 429].

Устранить данный недостаток стало возможным при использовании метода наименьших средних отклонений [Васильев 2010: 553-560]. В отличие от существующей методики («ближайших соседей»), предлагаемый подход использует результаты статистических расчетов при построении дерева и позволяет численно оценить надежность полученной классификации. При этом критерием «близости» двух языков является не единственное значение совпадений между их основными списками, а средняя величина абсолютного отклонения, вычисленная по совокупности долей совпадений рассматриваемой пары языков с каждым из остальных идиомов. Так, например, чтобы узнать величину отклонения (Е) для языков А и В в группе из 4-х языков (A, B, C, D), необходимо подсчитать разницу от их попарного сопоставления с каждым из 2-х других идиомов (C и D), а затем усреднить её:

$$
\mathrm{E}_{\mathrm{AB}}=\frac{\left|\mathrm{N}_{\mathrm{AC}}-\mathrm{N}_{\mathrm{BC}}\right|+\left|\mathrm{N}_{\mathrm{AD}}-\mathrm{N}_{\mathrm{BD}}\right|}{4-2}
$$

В общем случае расчет среднего абсолютного отклонения производится по формуле:

$$
\begin{aligned}
& \mathrm{E}_{\mathrm{ij}}=\frac{\sum_{\mathrm{k}=1}^{\mathrm{n}}\left|\mathrm{N}_{\mathrm{ki}}-\mathrm{N}_{\mathrm{kj}}\right|}{\sum_{\mathrm{k}=1}^{\mathrm{n}} \ell_{\mathrm{k}}}, \mathrm{k} \neq \mathrm{i}, \mathrm{k} \neq \mathrm{j} ; \mathrm{N}_{\mathrm{ki}} \leq \mathrm{N}_{\mathrm{ij}}, \mathrm{N}_{\mathrm{kj}} \leq \mathrm{N}_{\mathrm{ij}} ; \\
& \ell_{\mathrm{k}}=\left\{\begin{array}{l}
1 \text { при } \mathrm{k} \neq \mathrm{i}, \mathrm{k} \neq \mathrm{j}, \mathrm{N}_{\mathrm{ki}} \leq \mathrm{N}_{\mathrm{ij}}, \mathrm{N}_{\mathrm{kj}} \leq \mathrm{N}_{\mathrm{ij}} ; \\
0 \text { в остальных случаях }
\end{array}\right.
\end{aligned}
$$

где $\mathrm{n}$ - общее число языков в группе, а $\mathrm{N}_{\mathrm{ki}}$ и $\mathrm{N}_{\mathrm{kj}}$ - доли совпадений языков і и ј с каждым третьим языком $\mathrm{k}$ из множества $\mathrm{n}$. 


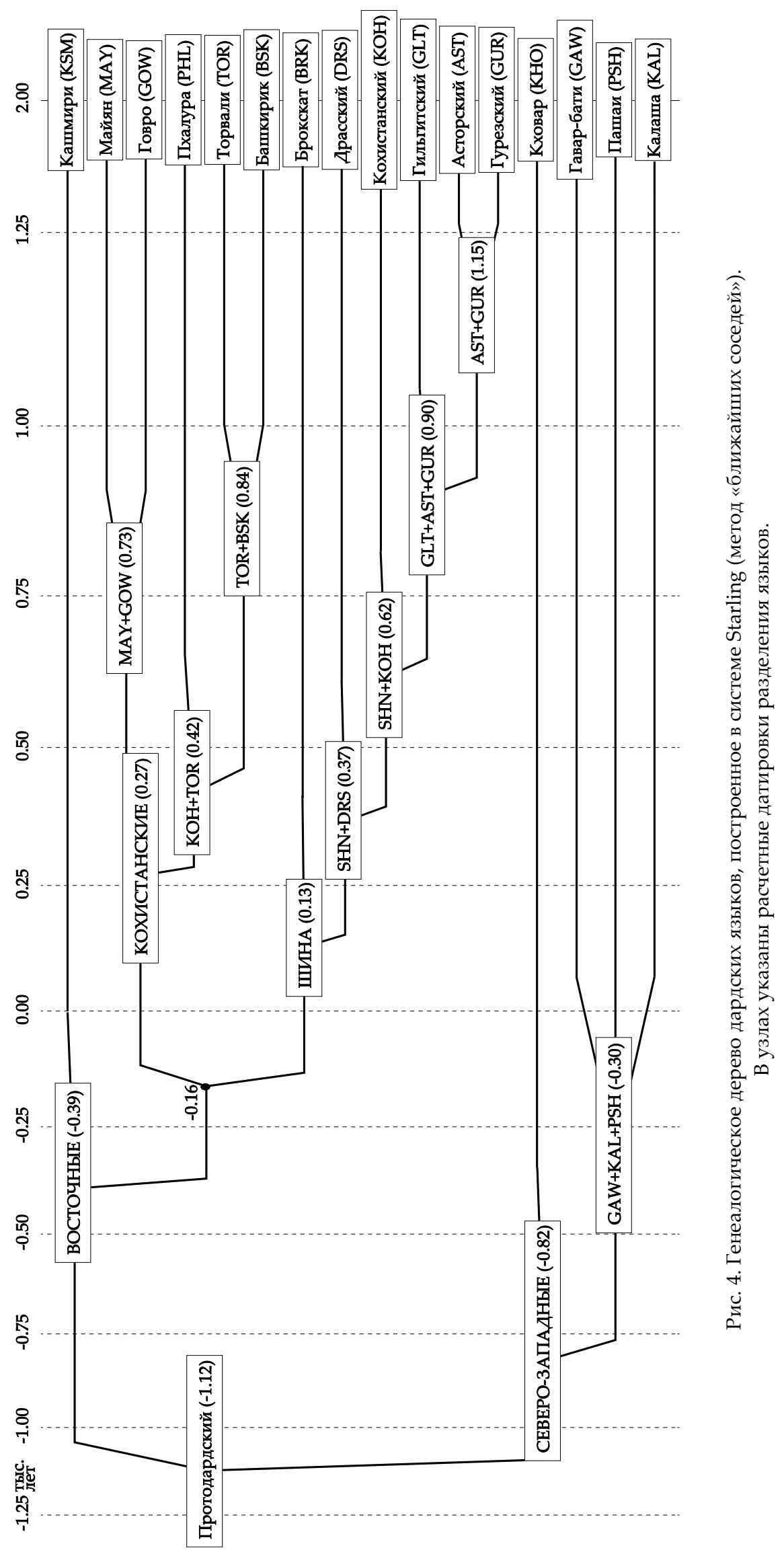


Таблица 4. Расчет среднего абсолютного отклонения (E $\mathrm{ELLTUR}_{\text {G }}$ для идиомов GLT и GUR (по данным табл. 1)

\begin{tabular}{|c|c|c|c|c|c|c|c|c|c|c|c|c|c|c|c|c|c|}
\hline № & Язык & $\begin{array}{c}1 \\
\text { KSM }\end{array}$ & $\begin{array}{c}2 \\
\text { GLT }\end{array}$ & $\begin{array}{c}3 \\
\text { BRK }\end{array}$ & $\begin{array}{c}4 \\
\text { PHL }\end{array}$ & $\begin{array}{c}5 \\
\text { GAW }\end{array}$ & \begin{tabular}{|c}
6 \\
PSH
\end{tabular} & $\begin{array}{c}7 \\
\text { KHO }\end{array}$ & $\begin{array}{c}8 \\
\text { KAL }\end{array}$ & $\begin{array}{c}9 \\
\text { MAY }\end{array}$ & $\begin{array}{c}10 \\
\text { TOR }\end{array}$ & $\begin{array}{c}11 \\
\text { DRS }\end{array}$ & $\begin{array}{c}12 \\
\text { AST }\end{array}$ & $\begin{array}{c}13 \\
\text { GUR }\end{array}$ & $\begin{array}{c}14 \\
\mathrm{KOH}\end{array}$ & $\begin{array}{c}15 \\
\text { GOW }\end{array}$ & $\begin{array}{c}16 \\
\text { BSK }\end{array}$ \\
\hline 2 & GLT & 0.63 & 1 & 0.78 & 0.72 & 0.61 & 0.53 & 0.48 & 0.6 & 0.73 & 0.71 & 0.84 & 0.9 & 0.92 & 0.9 & 0.71 & 0.71 \\
\hline 13 & GUR & 0.63 & 0.92 & 0.76 & 0.67 & 0.6 & 0.51 & 0.45 & 0.55 & 0.74 & 0.71 & 0.89 & 0.94 & 1 & 0.86 & 0.71 & 0.68 \\
\hline \multicolumn{2}{|c|}{$\left|\mathrm{N}_{\mathrm{k}, 2}-\mathrm{N}_{\mathrm{k}, 13}\right|$} & 0.00 & - & 0.02 & 0.05 & 0.01 & 0.02 & 0.03 & 0.05 & 0.01 & 0.00 & 0.05 & - & - & 0.04 & 0.00 & 0.03 \\
\hline \multicolumn{2}{|c|}{$\begin{array}{c}E_{2,13}= \\
=E_{\text {GLT-GUR }}\end{array}$} & \multicolumn{16}{|c|}{$E_{2,13}=$} \\
\hline
\end{tabular}

Таблица 5. Расчет среднего абсолютного отклонения (Е

\begin{tabular}{|c|c|c|c|c|c|c|c|c|c|c|c|c|c|c|c|c|c|}
\hline № & Язык & $\begin{array}{c}1 \\
\text { KSM }\end{array}$ & $\begin{array}{c}2 \\
\text { GLT }\end{array}$ & $\begin{array}{c}3 \\
\text { BRK }\end{array}$ & $\begin{array}{c}4 \\
\text { PHL }\end{array}$ & $\begin{array}{c}5 \\
\text { GAW }\end{array}$ & $\begin{array}{c}6 \\
\text { PSH }\end{array}$ & $\begin{array}{c}7 \\
\text { KHO }\end{array}$ & $\begin{array}{c}8 \\
\text { KAL }\end{array}$ & $\begin{array}{c}9 \\
\text { MAY }\end{array}$ & $\begin{array}{c}10 \\
\text { TOR }\end{array}$ & $\begin{array}{c}11 \\
\text { DRS }\end{array}$ & $\begin{array}{c}12 \\
\text { AST }\end{array}$ & $\begin{array}{c}13 \\
\text { GUR }\end{array}$ & $\begin{array}{c}14 \\
\text { KOH }\end{array}$ & $\begin{array}{c}15 \\
\text { GOW }\end{array}$ & $\begin{array}{c}16 \\
\text { BSK }\end{array}$ \\
\hline 12 & AST & 0.6 & 0.9 & 0.76 & 0.66 & 0.56 & 0.49 & 0.43 & 0.52 & 0.69 & 0.65 & 0.87 & 1 & 0.94 & 0.85 & 0.66 & 0.65 \\
\hline 13 & GUR & 0.63 & 0.92 & 0.76 & 0.67 & 0.6 & 0.51 & 0.45 & 0.55 & 0.74 & 0.71 & 0.89 & 0.94 & 1 & 0.86 & 0.71 & 0.68 \\
\hline \multicolumn{2}{|c|}{$\left|\mathrm{N}_{\mathrm{k}, 12}-\mathrm{N}_{\mathrm{k}, 13}\right|$} & 0.03 & 0.02 & 0.00 & 0.01 & 0.04 & 0.02 & 0.02 & 0.03 & 0.05 & 0.06 & 0.02 & - & - & 0.01 & 0.05 & 0.03 \\
\hline \multicolumn{2}{|c|}{$\begin{aligned} & E_{12,13}= \\
= & E_{\text {AST-GUR }}\end{aligned}$} & \multicolumn{16}{|c|}{ 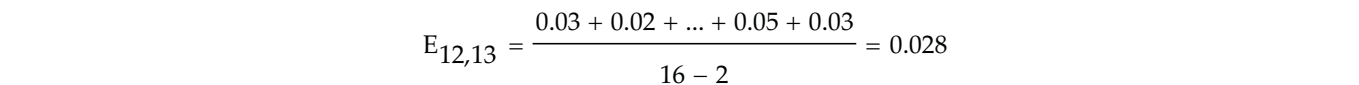 } \\
\hline
\end{tabular}

Очевидно, что пара идиомов і и $\mathrm{j}$, у которых величина среднего отклонения $\mathrm{E}_{\mathrm{ij}}$ будет минимальной, обладает совокупностью оценок $\mathrm{N}_{\mathrm{ki}}$ и $\mathrm{N}_{\mathrm{kj}}$, наиболее согласованных по отношению к остальным рассматриваемым языкам. В свою очередь это свидетельствует о наименьшей различимости основных списков этой пары языков, что в рамках модели дивергенции означает их позднейшее разделение. Следовательно, идиомы с наименьшим средним отклонением $\mathrm{E}_{\mathrm{ij}}$ обладают наиболее тесным родством внутри рассматриваемой группы, что позволяет объединить их в один узел на генеалогическом дереве.

Воспользуемся критерием наименьших средних отклонений для поиска ближайших родственников среди дардских языков. Проведенные подсчеты показывают, что искомой парой являются гильгитский (GLT) и гурезский (GUR) диалекты шина, абсолютное среднее отклонение которых составляет $\mathrm{E}_{\mathrm{GLT}-\mathrm{GUR}}=0,024$ (см. табл. 4).

Отметим, что найденная нами пара GLT-GUR отличается от выбранной используемым методом «ближайших соседей» пары AST-GUR, имеющей наибольшую долю совпадения основных списков $\left(\mathrm{N}_{\mathrm{AST}-\mathrm{GUR}}=0,94\right)$. Однако абсолютное среднее отклонение для этих языков составляет 0,028 (см. табл. 5), что превышает значение EGLT-GUR, полученное для гильгитского и гурезского и являющееся наименьшим:

$$
\mathrm{E}_{\text {GLT-GUR }}<\mathrm{E}_{\text {AST-GUR }}(0,024<0,028) .
$$

Соответственно, первый узел на генеалогическом дереве образуют не гурезский и асторский (как в случае с методом «ближайших соседей» - рис. 4), а гурезский и гильгитский диалекты. При этом вычисленное значение среднего абсолютного отклонения $\mathrm{E}_{\mathrm{ij}}$ составит доверительный интервал оценки $\mathrm{N}_{\mathrm{ij} .}$ Так, для первого узла дерева получаем:

$$
\mathrm{N}_{\text {GLT-GUR }}=\mathrm{N}_{2,13} \pm \mathrm{E}_{2,13}=0,92 \pm 0,024
$$

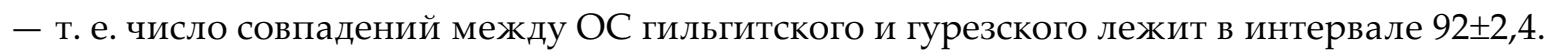


После объединения столбцов и строк GUR и GLT в табл. 1 производится очередной расчет значений $\mathrm{E}_{\mathrm{ij}}$ для всех оставшихся языков, и пара с наименьшим значением вновь объединяется. Данная процедура повторяется до тех пор, пока все идиомы и образованные ими группы не будут сведены в общий «корневой» узел дерева (рис. 5).

Наличие доверительных интервалов, рассчитанных для каждого случая разделения языков, позволяет нам наглядно установить наименее надежные узлы полученного дерева. В случае если значения соседних узлов взаимно перекрываются их доверительными интервалами, эти узлы можно считать статистически неразличимыми и объединить в один. Результирующий вид дерева после объединения узлов представлен на рис. 6.

Перейдем к сравнению полученных классификаций и обсуждению результатов.

Прежде всего отметим, что оба итоговых дерева (рис. 4 и 6) обнаруживают значительное сходство в иерархии и составе основных таксонов. Так, при любом способе классификации можно говорить о выделении трех обособленных ветвей: восточной (кашмири, кохистанские+шина), северо-западной (калаша, гавар-бати, пашаи) и, возможно, ветви кховар, - при этом группировка идиомов внутри каждой из них также во многом идентична.

Вместе с тем, применение метода наименьших средних отклонений позволило установить узлы дерева, обладающие низкой надёжностью. В частности, значительная статистическая погрешность мешает более точной дифференциации внутри группы шина (драсский, асторский, кохистанский): средняя доля совпадений $\mathrm{N}=87$ этих языков имеет сравнительно большой для данной временной глубины доверительный интервал: $\pm 3,8$ значения. Аналогичный вывод можно сделать для языка пашаи, узел подсоединения которого в структуру дерева также имеет неоправданно большой доверительный интервал: $\pm 6,8$ значений.

Все подобные случаи требуют дополнительного анализа обозначенных стословных списков на предмет возможных заимствований или ложных этимологических сравнений. Выявление этих неточностей позволит внести необходимые дальнейшие уточнения в итоговую классификацию.

Тем не менее, полученные результаты уже сейчас позволяют сделать ряд важных выводов о генеалогии дардских языков и, в частности, о справедливости восточнодардской гипотезы, изложенной выше. Как можно видеть на рис. 4, 5 и 6, восточнодардские языки выделяются как обособленная группа при использовании обоих методов лексикостатистической классификации: разновидности метода «ближайших соседей», реализованной в системе Starling, и метода наименьших средних отклонений. При этом разрыв между «протодардским» и восточнодардским узлами дерева, составляющий 8 значений, представляется достаточно широким, чтобы с уверенностью говорить именно о генетической близости, а не о вторичном лексическом сближении, вызванном языковыми контактами $^{32}$. Примечательно также, что доверительный интервал общевосточнодардского узла ( \pm 4 значения при средней доле совпадений $N=64$ ) не включает в себя значение общедардского узла $(\mathrm{N}=56)$, что свидетельствует о высокой надёжности выделения восточнодардской подгруппы.

Внутреннее членение восточнодардской языковой общности в обеих вышеприведенных классификациях несколько отличается от того, которое предлагалось в классификационной схеме Дж. Грирсона. Прежде всего это относится к генетическим отношениям языков кашмири и шина. Предполагавшаяся ранее особая близость этих языков и

32 Последние, как известно, могут приводить к завышению процента совпадений между основными списками близкородственных языков, но величина этого завышения может составлять максимум 5-6\% [Starostin 2000, 257]. 


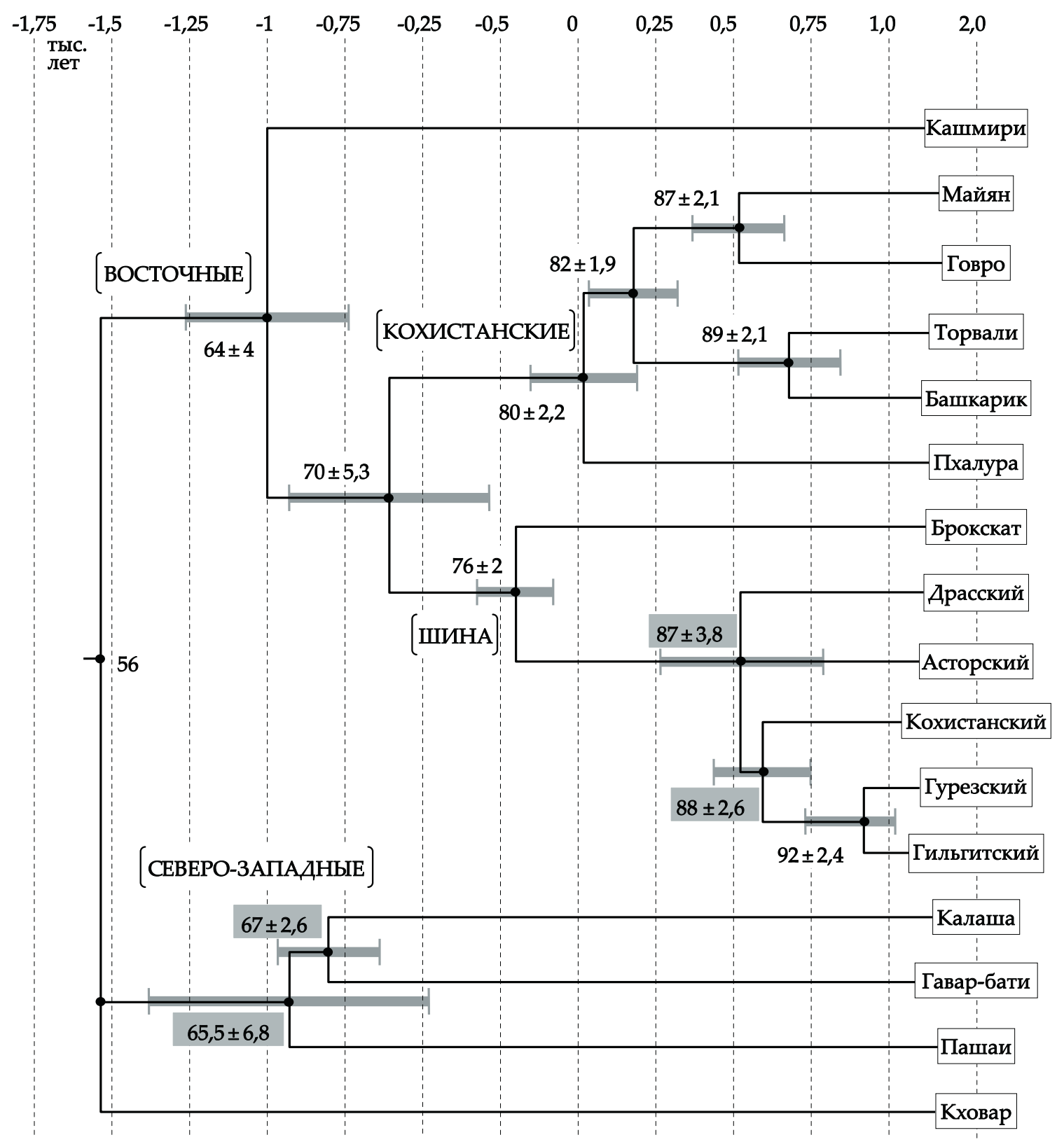

Рис. 5. Генеалогическое дерево дардских языков, построенное методом наименьших средних отклонений. Около каждого узла приводится доля совпадения основных списков и отклонение, указывающее границы доверительного интервала (в \%). Значения с обоюдно перекрывающимися доверительными интервалами выделены заливкой.

необходимость их объединения в отдельную подгруппу, противостоящую кохистанским языкам, не подтверждается лексикостатистическими данными. Наиболее тесное родство с диалектами шина обнаруживает как раз кохистанская подгруппа, в то время как кашмири выделяется в отдельную подветвь. В то же время, доверительный интервал средней доли шина-кохистанских совпадений $(\mathrm{N}=70)$, является чрезмерно широким и составляет \pm 5,3 значения, что превышает доверительные интервалы всех узлов древа, за исключением ненадёжного узла пашаи. Это даёт основания усомниться в наличии шина-кохистанской языковой общности. 


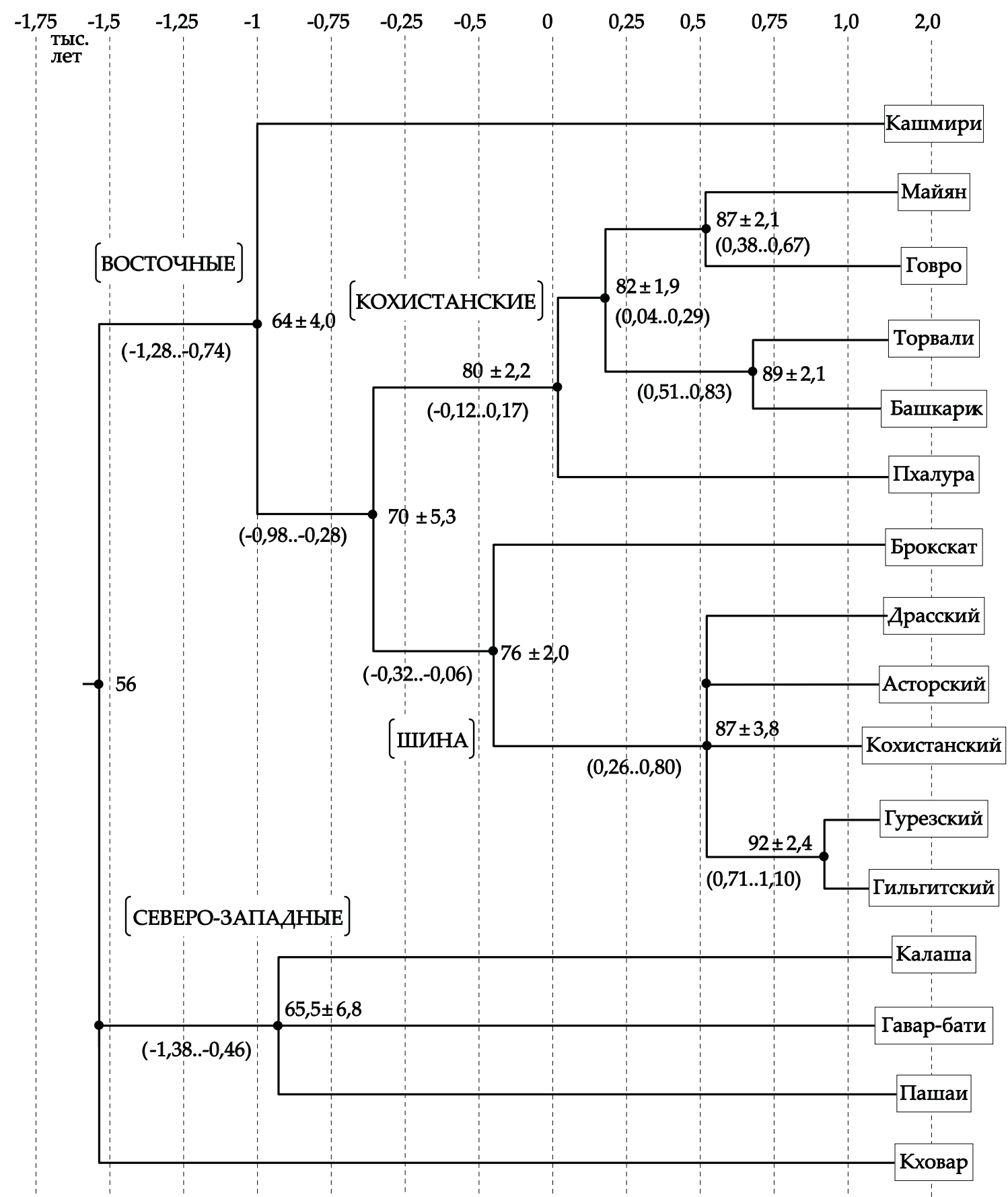

Рис. 6. Генеалогическое дерево дардских языков, построенное методом наименьших средних отклонений (узлы с перекрывающимися доверительными интервалами объединены). Около каждого узла приводится доля совпадения основных списков и отклонение, задающее границы доверительного интервала (в \%).

В скобках - соответствующие этим границам временные значения (тыс. лет).

Повышенный процент совпадений между диалектами шина и кохистанскими языками можно объяснить как генетической близостью, так и, например, наличием невыявленных заимствований и/или совместными лексическими инновациями, возможными при контактах близкородственных языков. Последнее особенно вероятно, если учитывать, что кохистанский языковой ареал непосредственно граничит с ареалом языка ши- 
на $^{33}$. Примечательно также и то, что до сих пор не выявлено ни одной историкофонетической изоглоссы, объединяющей шина со всеми кохистанскими языками в противовес кашмири.

Обращает на себя внимание и тот факт, что языки кохистанской подгруппы обнаруживают определенную лексическую близость не только с шина, но и с кашмири. Такой вывод можно сделать на основании повышенных процентов кашмирско-кохистанских совпадений, приведенных в табл. 1. С языками торвали и говро кашмири показывает $67 \%$ совпадений, с языками майян и башкарик - 68\%, т.е. на $3-4 \%$ больше средней восточнодардской доли схождений и на 5-6\% больше доли схождений между кашмири и диалектами шина ${ }^{34}$. Причиной такого относительно небольшого превышения, разумеется, могут быть языковые контакты, однако это не делает приведенные здесь цифры менее интересными. Дело в том, что кохистанский языковой ареал в настоящее время не граничит с кашмирским и довольно далеко отстоит от него географически (рис. 7). Данные лексикостатистики показывают, что в прошлом положение было иным. Кашмири и кохистанские языки должны были непосредственно соседствовать друг с другом, причем такую ситуацию следует предполагать вне зависимости от того, объясняется ли кашмирско-кохистанская лексическая близость тесным родством (что означает помимо прочего наличие общей прародины) или языковыми контактами.

Показательно, что доли совпадения между основными списками кашмири и диалектов шина относительно невысоки. Как правило, они являются более низкими, чем средняя восточнодардская доля совпадений ${ }^{35}$. Данный факт представляется особенно интересным, если учесть, что ареал шина (в частности, долины Гуреза и Драса) в настоящее время непосредственно примыкает к Кашмирской долине.

Объяснить данное положение вещей чрезвычайно трудно, если не предположить наличие в прошлом массовых миграций населения. В нашей недавней работе [Коган 2011] было показано наличие в языке кашмири следов индоарийского (новоиндийского) субстрата. Там же была высказана гипотеза, согласно которой носители дардского языка - предка кашмири заселили Кашмирскую долину в относительно недавнее время (в эпоху Средневековья, хронологически соответствующую ранней новоиндийской эпохе в истории индоарийских языков), что привело к постепенной ассимиляции прежних индоязычных жителей. При этом исходным пунктом дардской миграции, возможно, являлась долина р. Сват ${ }^{36}$, с которой средневековый Кашмир поддерживал регулярные контакты.

Данная гипотеза, базировавшаяся на анализе как лингвистического, так и исторического материала, теперь может быть подкреплена новыми фактами. Долина Свата находится в непосредственном соседстве с Кохистаном, однако при этом не граничит с ареалом шина. Естественно предположить, что предки современных кашмирцев, проживая (возможно, в течение многих веков) в этой долине или где-то вблизи неё до переселения в Кашмир, находились в тесном и постоянном контакте с предками кохистанцев. С этим

33 В прошлом ситуация, по всей видимости, была еще более благоприятной для языковых контактов. Считается, что восточная, не примыкающая к Кохистану часть нынешнего шинаязычного ареала, включающая в частности гильгитскую долину, была заселена мигрировавшими с запада шина в относительно позднее время, уже в средние века (об этом см., напр., [Йеттмар 1986]). До этого времени все носители диалектов шина (или их общего языка-предка), вероятнее всего, проживали в непосредственном соседстве с кохистанским ареалом.

${ }^{34}$ Средний процент совпадений между кашмири и диалектами шина составляет приблизительно 62\%.

35 Исключение составляет только диалект брокскат, для которого доля совпадений с кашмири равна общевосточнодардской.

${ }^{36}$ Девый приток р. Кабул. Ныне на северо-западе Пакистана. 


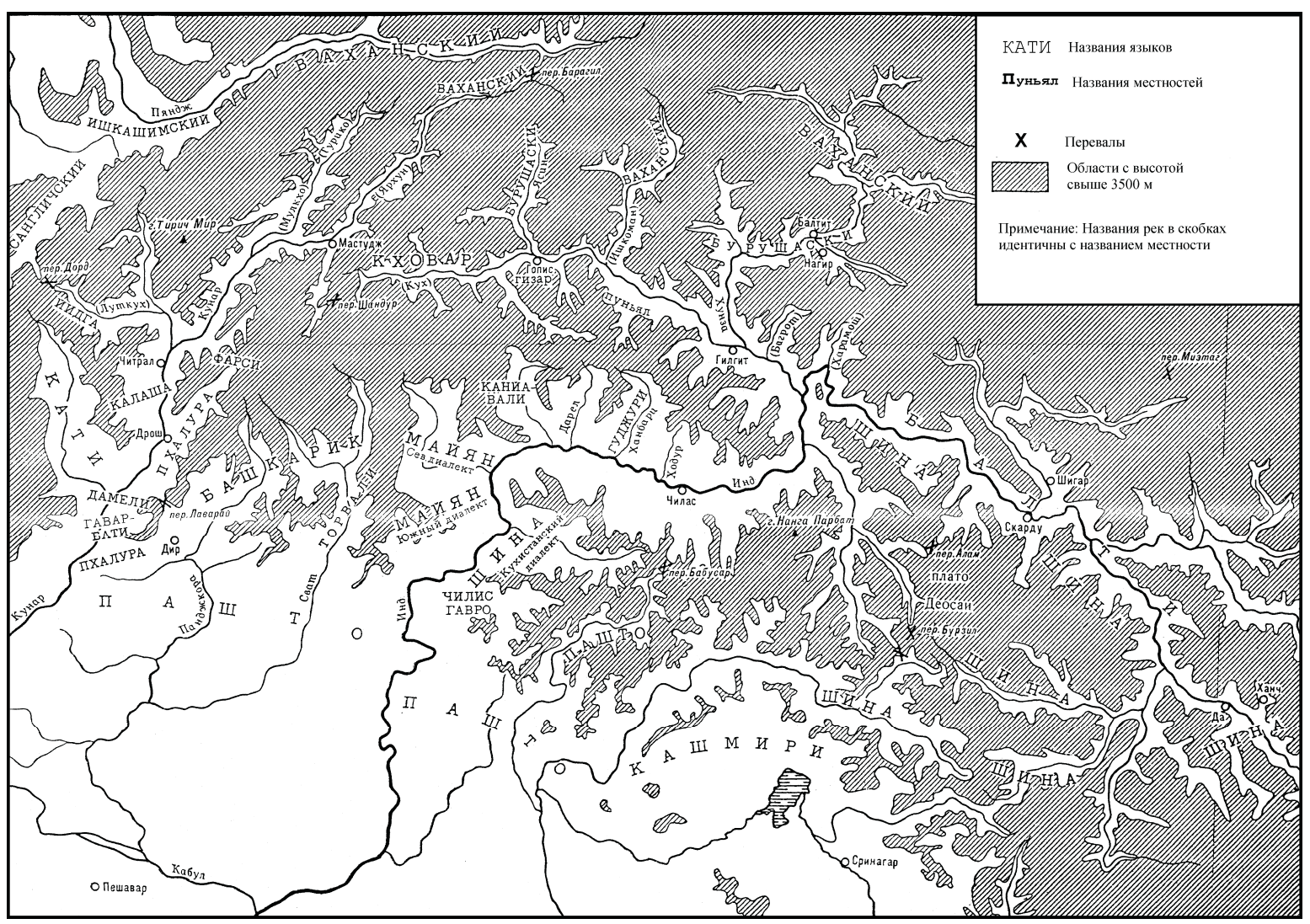

Рис. 7. Языки восточнодардской подгруппы и важнейшие соседние языки (по книге: К. Йеттмар, «Религии Гиндукуша». М., 1986)

и может быть связан вышеупомянутый «подскок» в долях совпадений между основными списками кашмири и кохистанских языков. Непосредственного же контакта с носителями шина не было, он стал возможен существенно позже, уже во время проживания в Кашмирской долине. К началу этого периода языки шина и кашмири, вероятнее всего, успели разойтись весьма значительно, и развитие совместных лексических инноваций было крайне затруднено. Это позволяет объяснить относительно невысокие (несмотря на нынешнее соседство языков) доли шина-кашмирских совпадений. Кохистан должен был в течение весьма долгого времени играть роль своеобразного клина, разделявшего область распространения шина и ареал языка - предка кашмири. С этим, возможно, связан тот факт, что кохистанские языки обнаруживают высокий процент схождений как с кашмири, так и с диалектами шина.

Полученные выше результаты, а также их последующий сравнительный анализ в очередной раз убеждают в том, что метод лексикостатистики (при адекватном его использовании) позволяет не только строить генетические классификации, но и формировать определенное представление о лингвистической географии, этнических миграциях и межъязыковых контактах в продолжительной временной перспективе. 


\section{Сокращения}

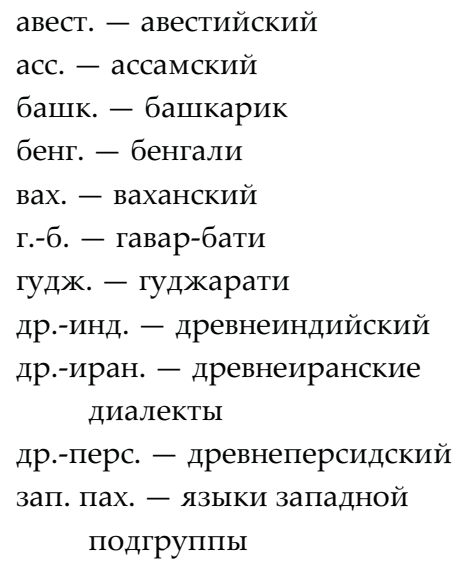

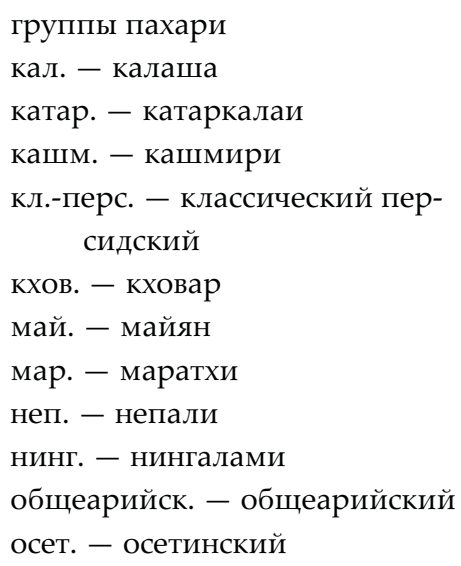

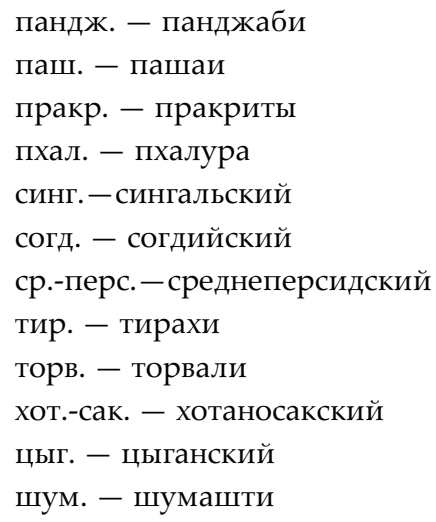

\section{Питература}

Бурлак, Старостин 2005 - БурлАк С. А., СТАРОстин С. А. Сравнительно-историческое языкознание. М.: Академия, 2005. 432 с. [BURLAK S. A., STAROSTIN S. A. Sravnitel'no-istoricheskoe yazykoznanie. M.: Akademiya, 2005. $432 \mathrm{s.}]$

Васильев 2010 - ВАСИЛЬЕВ М. Е. Об использовании лексического критерия для построения генеалогической классификации // Бюлетень Общества востоковедов РАН. Вып. 17. М.: Институт востоковедения PAH, 2010. Стр. 530-572. [VASILYEV M. E. Ob ispol'zovanii leksicheskogo kriteriya dlya postroeniya genealogicheskoj klassifikacii // Byulleten' Obschestva vostokovedov RAN. Vyp. 17. M.: Institut vostokovedeniya RAN, 2010. Str. 530-572.]

Грюнберг 1971 - ГрюнБерг А. А. К диалектологии дардских языков (глангали и земиаки) // Индийская $u$ иранская филология. Вопросы диалектологии. М., 1971. [GRYUnBerG A. L. K dialektologii dardskikh yazykov (glangali i zemiaki) // Indijskaya i iranskaya filologiya. Voprosy dialektologii. M., 1971.]

Йеттмар 1986 - Йеттмар К. Религии Гиндукуша. М., 1986. [JetтмаR K. Religii Gindukusha. M., 1986.]

Коган 2005 - КоГАН А. И. Дардские языки. Генетическая характеристика. М., Восточная литература, 2005. [KogAn A. I. Dardskie yazyki. Geneticheskaya kharakteristika. M., Vostochnaya literatura, 2005.]

Коган 2007 - КОГАН А. И. Дардские и нуристанские элементы в языке дамели // Orientalia et classica: mpyды Института восточных культур и античности. Выпуск XI. Аспекты компаративистики 2. М., РГГУ, 2007. Стр. 310-327. [KoGAN A. I. Dardskie i nuristanskie elementy v yazyke dameli // Orientalia et classica: trudy Instituta vostochnykh kul'tur i antichnosti. Vypusk XI. Aspekty komparativistiki 2. M., RGGU, 2007. Str. 310-327.]

Коган 2011 - КоГАН А. И. К характеристике индоарийских элементов в языке кашмири // Вестник РГГУ. Научный журнал. Серия «Филологические науки. Языкознание». Вопросы языкового родства, №5, 2011. Стр. 23-47. [KoGAN A. I. K kharakteristike indoarijskikh elementov v yazyke kashmiri // Vestnik RGGU. Nauchnyj zhurnal. Seriya «Filologicheskie nauki. Yazykoznanie». Voprosy yazykovogo rodstva, №5, 2011. Str. 23-47.]

Старостин 2007 - СТАРостин С. А. Сравнительно-историческое языкознание и лексикостатистика // СТАрОстин С. А. Труды по языкознанию. М.: Языки славянских культур, 2007. Стр. 407-447. [STAROSTIN S. A. Sravnitel'no-istoricheskoe yazykoznanie i leksikostatistika // STAROSTIN S. A. Trudy po yazykoznaniyu. M.: Yazyki slavyanskikh kul'tur, 2007. Str. 407-447.]

Эдельман 1992 - ЭдЕльмАН Д. И. Еще раз об этапах филиации арийской языковой общности // Bопросы языкознания, № 3, 1992. Стр. 44-66. [EDELMAN D. I. Esche raz ob etapakh filiacii arijskoj yazykovoj obschnosti // Voprosy yazykoznaniya, № 3, 1992. Str. 44-66.]

Buddruss 1960 - BudDruss G. Die Sprache von Wotapur und Katarqala. Bonn, 1960.

Buddruss 1977 - BUDDRUSS G. Nochmals zur Stellung der Nuristan-Sprachen des afghanischen Hindukusch // Münchener Studien zur Sprachwissenschaft. H. 36. München, 1977.

Edelman 1983 - EDELMAN D. I. The Dardic and Nuristani languages. Moscow, 1983. 
Grierson 1919 - Grierson G. A. Linguistic Survey of India. Vol. VIII, pt. 2. Specimens of the Dardic or Piśāca Languages (including Kāshmìrì). Calcutta, 1919.

Grierson 1927 - Grierson G. A. Linguistic Survey of India. Vol. I, pt. 1. Introductory. Calcutta, 1927.

Grierson 1929 - Grierson G. A. Torwali, an Account of a Dardic Language of the Swat Kohistan. L., 1929.

Grierson 1969 - Grierson G. A. The Piśäca languages of North-Western India. Delhi, 1969 [Repr.].

Kassian et al. 2010 - Kassian A., Starostin G., Dybo A., Chernov V. The Swadesh wordlist. An attempt at semantic specification // Вестник РГГУ. Научный журнал. Серия «Филологические науки. Языкознание». Вопросы языкового родства, №4, 2010, стр. 46-89.

Morgenstierne 1926 - Morgenstierne G. Report on a Linguistic Mission to Afghanistan. Oslo, 1926.

Morgenstierne 1932 - Morgenstierne G. Report on a Linguistic Mission to North-Western India. Oslo, 1932.

Morgenstierne 1941 - Morgenstierne G. Notes on Phalura, an Unknown Dardic Language of Chitral // Skrifter utgitt av Det Norske Videnskaps Akademi i Oslo. Hist. - Filos. Klasse, 1940, No. 5, Oslo, 1941.

Morgenstierne 1942 - Morgenstierne G. Notes on Dameli, a Kafir-Dardic Language of Chitral // Norsk Tidsskrift for Sprogvidenskap. Bd. XII. Oslo, 1942.

Morgenstierne 1945 - MORGENSTIERnE G. Indo-European k' in Kafiri // Norsk Tidsskrift for Sprogvidenskap. Bd. XIII. Oslo, 1945.

Morgenstierne 1961 - Morgenstierne G. Dardic and Kafir Languages // The Encyclopedia of Islam. Vol. 2, Fasc. 25. Leiden, Brill, 1961.

Online Torwali Dictionary 2011 - Center for Language Engineering. Online Torwali Dictionary: http://www.cle.org. $\mathrm{pk} /$ software/ling_resources/otd.htm

Starostin 2000 - STAROSTIN S. Comparative-historical linguistics and lexicostatistics // Time Depth in Historical Linguistics / The McDonald Institute for Archaeological Research Publications. Vol. 1. Cambridge: Blue Print, 2000, pp. 223-259.

Schmidt, Kaul 2008 - Schmidt R. L., KAUl V. K. A Comparative Analysis of Shina and Kashmiri Vocabularies // Acta Orientalia, 69, 2008, pp. 231-302.

Strand 1973 - STRAND R. F. Notes on Nuristani and Dardic Languages // Journal of the American Oriental Society. Vol. 93, No. 3, New Haven, 1973.

Strand 2006 - STRAND R. F. Phylogenetic Classification of the Region's Languages: http://nuristan.info/lngIndex0.html Woolner 1917 - WoOLNER A. C. Introduction to Prakrit. Calcutta, 1917.

Zoller 2005 - Zoller C. P. A Grammar and Dictionary of Indus Kohistani. Volume 1: Dictionary. Berlin - New-York, Mouton de Gruyter, 2005.

\section{Придожение. \\ Стословные списки дардских языков и диалектов}

После каждой формы в скобках дается номер её этимологии в базе данных. Все лексемы с общей этимологией имеют одинаковые номера. Для заимствований используется отрицательная нумерация. Обозначения языков: KSM - кашмири, GLT - гильгитский диалект шина, BRK - брокскат, PHL - пхалура, GAW - гавар-бати, PSH - пашаи, KHO - кховар, KAL - калаша, MAY - майян, TOR - торвали, DRS - драсский диалект шина, AST - асторский диалект шина, GUR - гурезский диалект шина, КОН - кохистанский диалект шина, GOW - говро, BSK - башкарик.

1 all: KSM soruy [1]; GLT buṭu [164]; BRK čok [-1]; PHL buṭäi [164]; GAW sumi [254]; PSH čuika [315]; KHO čhīk [315], saf [1]; KAL čik [315], sao [1]; MAY buṭ [164]; TOR buṭ [164]; DRS buče [164], lā [490]; AST buțe [164]; GUR buți [164], lā [490]; KOH buța [164]; GOW sav [1]; BSK s(ū)o [1].

2 ashes: KSM sūr [3]; GLT dal [195]; BRK thaltsir [-2]; PHL dal [195], čhī [514]; GAW sāga [2]; PSH āsək [2]; KHO pheru [349]; KAL șuțik [394]; MAY nigal [-1]; TOR pono [480]; DRS dāl [195]; AST dāl [195]; GUR dāl [195]; KOH šō [511]; GOW swāa [2]; BSK čč [514]. 
3 bark: KSM d'al [4]; GLT dilu [4]; BRK pharput [431]; PHL patțaṛa [120], līnču [226]; GAW cīk [264]; PSH čìk [264], čalak [316]; KHO lenžu [226]; KAL potoŕi [120]; MAY dil [4]; TOR pār [120]; DRS dilo [4]; AST dilo [4]; GUR delu [4]; KOH dilo [4]; GOW (?); BSK pir [120].

4 belly: KSM yed [5]; GLT der [121]; BRK wār [121]; PHL dhēr [121]; GAW war [121]; PSH kūč [317]; KHO khoyanu [350]; KAL kuč [317]; MAY vayri [121]; TOR ḍhe [121], d̦am [515]; DRS ḍer [121]; AST dẹr [121]; GUR dẹer [121]; KOH dẹer [121]; GOW ḍ(h)er [121]; BSK dẹar [121].

5 big: KSM boḍ [6]; GLT boru [6]; BRK bōno [6]; PHL ghānu [122]; GAW dal [246]; PSH aulā [318], gan [122]; KHO loṭ [351]; KAL luṭ [351], gona [122]; MAY gahũ [122]; TOR g(h)an [122]; DRS baro

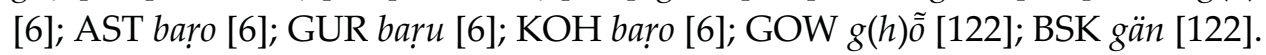

6 bird: KSM jānawār [-1]; GLT bring [196]; BRK čey [227]; PHL čäluṭi [227]; GAW phēçin [123]; PSH paș̌in [123]; KHO boik [352]; KAL paç̌ĩyak [123]; MAY caklu [227]; TOR peș̌īn [123]; DRS čäĩ

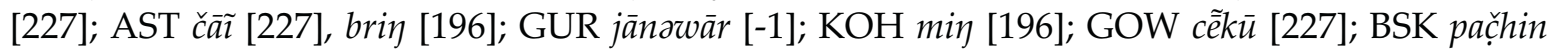
[123].

7 bite: KSM cop hi- [8]; GLT čap- [8], žan tho- [197]; BRK čaך th- [197]; PHL čuk- [228]; GAW cep[8]; PSH čor- [319]; KHO don čhok- [353]; KAL čhund- [319]; MAY cap- [8]; TOR çugū- [481]; DRS jan thi- [197]; AST jan thō- [197]; GUR čap- [8]; KOH čap- [8]; GOW cap- [8]; BSK (?).

8 black: KSM krehon [9]; GLT kinu [9]; BRK kyono [9]; PHL kiṣ̆iṇu [9]; GAW khãca [265]; PSH šāmāk [320]; KHO šā [320]; KAL križna [9]; MAY kišũ [9]; TOR kiṣ̆an [9]; DRS kino [9]; AST kiṇo [9]; GUR kiṇo [9]; KOH kiṇo [9]; GOW kyen [9]; BSK kiṣ̆än [9].

9 blood: KSM rath [10]; GLT lel [198]; BRK lol [198]; PHL rāt [10]; GAW lō [198]; PSH ār [321]; KHO ley [198]; KAL lui [198]; MAY rat [10]; TOR žăt [10]; DRS lēl [198]; AST lēl [198]; GUR lēl [198]; KOH lèl [198]; GOW rat(ah) [10]; BSK rat [10].

10 bone: KSM aḍij [11]; GLT ãți [11]; BRK āțți [11]; PHL haddung [-1]; GAW haḍ [-1]; PSH ațthī [11]; KHO astī [11], kōl [354]; KAL ațhi [11]; MAY hạ [-2]; TOR hār [-1]; DRS ați [11]; AST ãți [11]; GUR ãți [11]; KOH ãți [11]; GOW hār [-1]; BSK haḍ [-1].

11 breast: KSM wačh [12], than [429]; GLT čuči [124], titìru NW [199]; BRK dut [432], kro [229]; PHL čiči [124], kiror [229]; GAW cucū [124], hida [266]; PSH čučù [124]; KHO pap [-1]; KAL čūčù [124], kŕura [229]; MAY cwic [124]; TOR buk [482]; DRS mamẽ [463]; AST mam [463]; GUR mamu [463]; KOH čiči [124]; GOW cuci [124]; BSK čič [124], irgaṇd [522].

12 burn tr.: KSM zāl- [-2]; GLT day- [13], lup- [200]; BRK dāh- [13]; PHL dajū- [13], le- [230]; GAW loš- [267]; PSH jutal- [322]; KHO pale- [355]; KAL upuw- [395]; MAY daz- [13]; TOR d(h)ažaw- [13]; DRS day- [13]; AST day- [13]; GUR day- [13]; KOH dah- [13]; GOW daz- [13]; BSK juk- [523].

13 claw (nail): KSM nam [14]; GLT nōru [14]; BRK nēri [14]; PHL nōyg [14]; GAW nak [14]; PSH nawarī [14]; KHO doyur [-2]; KAL najguš [14]; MAY nakh [14]; TOR nokh [14]; DRS nōr [14]; AST nōr [14]; GUR nōr [14]; KOH nūro [14]; GOW nākh [14]; BSK nakh [14].

14 cloud: KSM obur [15]; GLT ažu [15]; BRK ažeș [15]; PHL ābru [15]; GAW albena [15]; PSH nalī [15]; KHO koț [356]; KAL minj [396]; MAY až [15]; TOR ag(h)ā [15]; DRS ažo [15]; AST ažo [15]; GUR aj̣u [15]; KOH ažo [15]; GOW až [15]; BSK āga [15].

15 cold: KSM šehol [16], tūrun [17]; GLT šidalu [126]; BRK čūa [434]; PHL šidālo [126]; GAW šola [16]; PSH šidāl [126]; KHO šaru [16], ušak [126]; KAL oš [126]; MAY tu [17]; TOR šìdal [126]; DRS

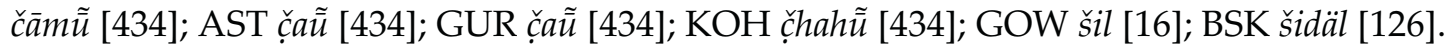


16 come: KSM yi- [18]; GLT yay- [18], way- [167]; BRK e- [18]; PHL yh- [18], yōl- [231]; GAW ži[18], aya- [231]; PSH yei- [18]; KHO go- [231]; KAL i- [18], a- [231]; MAY i- [18]; TOR yew- [18]; DRS ō- [18]; AST waz- [167]; GUR ō- [18]; KOH ay- [18]; GOW yō [18]; BSK yā- [18].

17 die: KSM mar- [19]; GLT mir- [19]; BRK min- [19]; PHL mār- [19]; GAW mi- [19]; PSH le- [19]; KHO br- [19]; KAL naš- [397]; MAY mar- [19]; TOR mow- [19]; DRS mir- [19]; AST mir- [19]; GUR mir- [19]; KOH mir- [19]; GOW marãv [19]; BSK mar- [19].

18 dog: KSM hūn [20]; GLT šũ [20]; BRK ș̌va [20]; PHL kučuro [127]; GAW šunā [20]; PSH šūig [20]; KHO rēni [357]; KAL šũu(r)a [20]; MAY kucuru [127]; TOR kužū [127]; DRS š $\tilde{u}$ [20]; AST š $\tilde{u}$ [20]; GUR š $\tilde{u}$ [20]; KOH š̃u [20]; GOW kucar [127]; BSK kučur [127].

19 drink: KSM či- [21]; GLT pi- [128]; BRK pī- [128]; PHL pi- [128]; GAW pi- [128]; PSH pi- [128]; KHO pi- [128]; KAL pi- [128]; MAY pu- [128]; TOR pu- [128]; DRS pi- [128]; AST pi- [128]; GUR pi- [128]; KOH pi- [128]; GOW põ [128]; BSK pu- [128].

20 dry: KSM hokh [22]; GLT šūku [22]; BRK šuko [22]; PHL šuko [22]; GAW šukha [22]; PSH sus[22]; KHO ç̣ūç̌hu [22]; KAL luç̌ha [398], ș̌uș̌ț [22]; MAY šikh [22]; TOR šūžel [22]; DRS šuko [22]; AST šuku [22]; GUR šuku [22]; KOH šukho [22]; GOW šikēl [22]; BSK šukh [22].

21 ear: KSM kan [23]; GLT kon [23]; BRK kani [23]; PHL kan [23]; GAW khamța [23]; PSH kan [23], khāi [323]; KHO kar [23]; KAL kŕũ [23]; MAY kaṇ [23]; TOR kān [23]; DRS kon [23]; AST koṇ [23]; GUR kon [23]; KOH kon [23]; GOW kan(ah) [23]; BSK kaṇ [23].

22 earth: KSM butrāt [24], mac [25]; GLT sum [129]; BRK pe [435]; PHL sum [129]; GAW bum [24], sum [129]; PSH bùm [24], sāyg [129]; KHO bum [24], çhuti [427]; KAL bhum [24], phau [399]; MAY māch [25], dharz்̃ [453]; TOR d(h)erīn [453], sum [129]; DRS kwī [491]; AST sum [129]; GUR mōtți [25]; KOH sum [129]; GOW d(h)arz̃ [453]; BSK bum [24], sum [129], darin [453].

23 eat: KSM khi- [26]; GLT kho- [26]; BRK xa- [26]; PHL khuw- [26]; GAW žu- [268]; PSH ay[324], žū- [268]; KHO žib- [268]; KAL žu- [268]; MAY khā- [26]; TOR khow- [26]; DRS khō- [26]; AST khō- [26]; GUR khō- [26]; KOH khō- [26]; GOW khayõ [26]; BSK khā- [26].

24 egg: KSM țhūl [27]; GLT haṇe [130]; BRK țhul [27], ane [130]; PHL haṇo [130]; GAW anda [130]; PSH āndā [-1]; KHO ayukun [358]; KAL ondrak [130], ayukun [358]; MAY ãra [130]; TOR $\bar{a} n$ [130]; DRS țhūl [27]; AST thūl [27]; GUR țhūl [27]; KOH haṇo [130]; GOW aṭe [130]; BSK aṇ [130].

25 eye: KSM əčh [28]; GLT aç̌hi [28]; BRK aç̌hī [28]; PHL aç̌hi [28]; GAW icīn [28]; PSH ačhī [28];

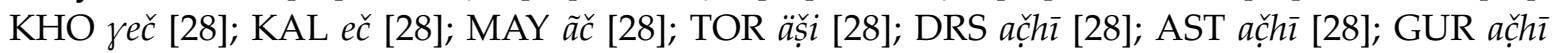
[28]; KOH aç̌hī [28]; GOW aç̌e [28]; BSK ēç [28].

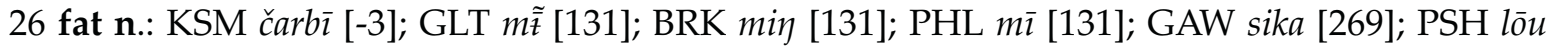

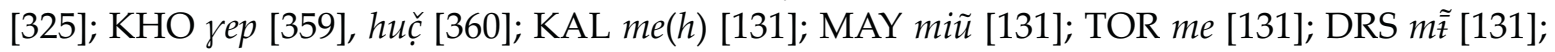

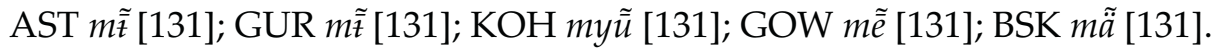

27 feather: KSM tīr [29]; GLT paç̌āli [361]; BRK ș̌okpā [-3]; PHL phātu [168]; GAW phațta [168]; PSH parr [-2]; KHO poç [361]; KAL paç̌ [361]; MAY pāçh [361]; TOR per [168]; DRS pato [168]; AST tìri [29]; GUR pațu [168]; KOH paçhāli [361]; GOW pāṣ̌e [361]; BSK (?).

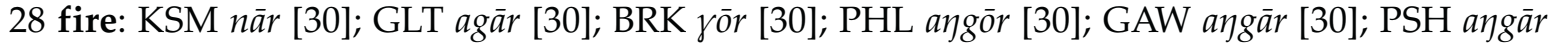

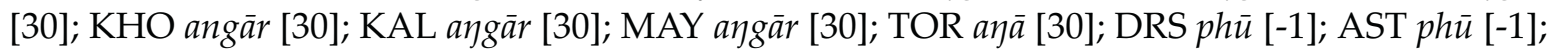
GUR ajgāru [30]; KOH phū [-1]; GOW nār [30]; BSK äygār [30]. 
29 fish: KSM gāẹ [31]; GLT čhimu [-1]; BRK nya [-4]; PHL remac [-2]; GAW macoṭa [132]; PSH mās [132]; KHO maci [132]; KAL (ū)maci [132]; MAY chim [-3]; TOR māš [132]; DRS čhimo [-2]; AST čhumo [-2]; GUR čhumo [-2]; KOH čhubo [-2]; GOW machī [132]; BSK macin [132].

30 fly v.: KSM wuph- [32]; GLT thar do- [203]; BRK up- [32]; PHL ub(h)r- [232]; GAW (?); PSH učund-[326]; KHO uli- [362]; KAL upul- [400]; MAY thar di- [203], šiš di- [454]; TOR šǐš dew[454]; DRS talwī di- [492]; AST tali di- [492]; GUR talē di- [492]; KOH thor do- [203]; GOW bar h[517]; BSK š̃̌̃̌s da- [454].

31 foot: KSM khor [33]; GLT pā [204]; BRK kutti [436]; PHL khur [33]; GAW khur [33]; PSH pā [204]; KHO poyg [204]; KAL khūr [33]; MAY khur [33]; TOR khū [33]; DRS pā [204]; AST pā [204]; GUR pā [204]; KOH pã [204]; GOW khur [33]; BSK khur [33].

32 full: KSM pūr [34]; GLT șak [205]; BRK punjis [34]; PHL punilo [34]; GAW pūr [34]; PSH purā [34]; KHO tip [-3]; KAL püri [34]; MAY põsil [34]; TOR punel [34]; DRS phūṇo [34]; AST ṣ̆ek [205]; GUR ș̆ek [205]; KOH phūṇo [34]; GOW pãyšẽy [34]; BSK čupuṭ [34].

33 give: $\mathrm{KSM}$ di- [35]; GLT do- [35]; BRK de- [35]; PHL de- [35]; GAW $\lambda i-$ [35]; PSH day- [35]; KHO do- [35], tare- [364]; KAL de- [35]; MAY di- [35]; TOR dew- [35]; DRS di- [35]; AST dō- [35]; GUR di- [35]; KOH do- [35]; GOW diyãv [35]; BSK da- [35].

34 good: KSM jān [36], rut [37]; GLT miș̣tu [186], šo [206]; BRK țhālo [437]; PHL šūo [206]; GAW bai [270]; PSH bai [270]; KHO jam [36]; KAL pruș̆t [401]; MAY miți [186]; TOR rorā [-2]; DRS sī [493], šaboko [206]; AST miș̌țu [186]; GUR miș̣thu [186], siyō [493]; KOH mișțho [186], sam [512]; GOW marnei [-2]; BSK rān [524].

35 green: KSM n’ūl [38]; GLT nìlu [38]; BRK yīlo [38]; PHL nìlu [38]; GAW nìla [38]; PSH sauz [-3]; KHO oč [365]; KAL lì [402]; MAY nīl [38]; TOR nil [38]; DRS nīlo [38]; AST nìlu [38]; GUR nìlu [38]; KOH nīlo [38]; GOW nīl [38]; BSK pala [525].

36 hair: KSM mas [430]; GLT jakur [207], čamoyẽ [208]; BRK žakor [207]; PHL bola [-3]; GAW cimuța [271], khẽs [272]; PSH žūtr [327]; KHO dro [366]; KAL čuŕi [403], jaj [404]; MAY bāl [-4]; TOR bāl [-3]; DRS jakū [207]; AST jāko [207]; GUR jakū [207]; KOH jāko [207]; GOW bāl [-3]; BSK $b \bar{a} l[-2]$.

37 hand: KSM atha [39]; GLT hat [39]; BRK hat [39]; PHL hāt [39]; GAW hast [39]; PSH hāst [39]; KHO host [39]; KAL hast [39]; MAY hā [39]; TOR hāt [39]; DRS hat [39]; AST hat [39]; GUR hat [39]; $\mathrm{KOH}$ hat [39]; GOW hat [39]; BSK thèr [526].

38 head: KSM hīr [40]; GLT șiš [40]; BRK šiš [40]; PHL șsiš [40]; GAW šauṭa [40]; PSH šî [40],

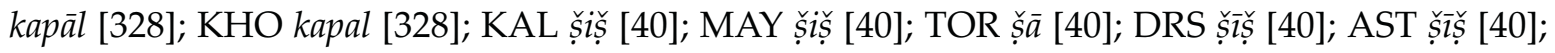

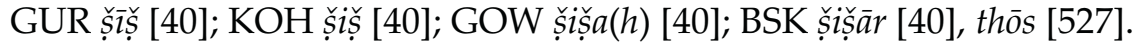

39 hear: KSM boz- [41]; GLT paruž- [41]; BRK kon th- [233]; PHL șun- [188], kãtha- [233]; GAW šuni- [188]; PSH ar- [329]; KHO kara do- [233]; KAL sayg(h)a- [405]; MAY ș̌u- [188]; TOR buž[41]; DRS parj- [41]; AST parj- [41]; GUR parj- [41]; KOH ș̣un- [188]; GOW șsō [188]; BSK bujj- [41].

40 heart: KSM dil [-4]; GLT hīu [138]; BRK ho [138]; PHL hị̣o [138]; GAW hị̣a [138]; PSH hār [138]; KHO hardi [138]; KAL h(r)iya [138]; MAY halali [138]; TOR hai [138]; DRS hīu [138]; AST hyū [138]; GUR hì (u) [138]; KOH hyū [138]; GOW halāli [138]; BSK ikukur [138].

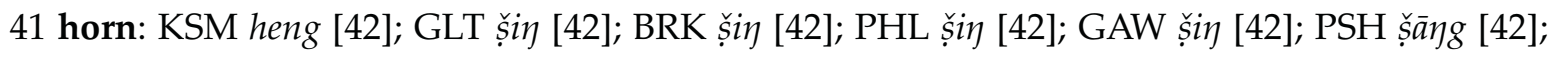

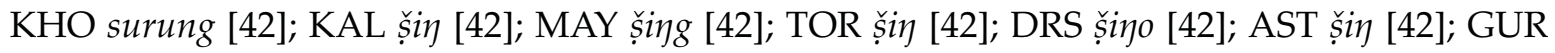
șiinu [42]; KOH șigo [42]; GOW ș̌ang [42]; BSK ș̌ī [42]. 
42 I: KSM bih [43], me [189]; GLT ma [189]; BRK mo [189]; PHL ma [189]; GAW à [189]; PSH $a$ [189]; KHO awa [189]; KAL ā [189]; MAY ma [189]; TOR ā [189]; DRS moh [189]; AST mũh [189]; GUR mu [189]; KOH mo [189]; GOW ma [189]; BSK ya [189].

43 kill: KSM mār- [44]; GLT mar- [44]; BRK mar- [44]; PHL mhārū- [44]; GAW mār- [44]; PSH mār- [44], (h)an- [330]; KHO mar- [44]; KAL mar- [44], hũr- [330]; MAY mār- [44]; TOR mow- [44]; DRS mar- [44]; AST mar- [44]; GUR mar- [44]; KOH mar- [44]; GOW mārã̃ [44]; BSK mār- [44].

44 knee: KSM koțh [45]; GLT kuṭo [45]; BRK kūṭo [45]; PHL khuțu [45]; GAW dụga [273]; PSH kār [331]; KHO zanu [-4]; KAL ḍễik [273]; MAY kuṭh [45]; TOR kud [45]; DRS kuțo [45]; AST kuṭo [45]; GUR kuṭu [45]; KOH kuțho [45]; GOW kuṭh [45]; BSK kūṭ [45].

45 know: KSM zān- [46]; GLT daș̆t- [209], sũy- [518]; BRK žu- [438]; PHL jhan- [46]; GAW pian[46]; PSH piēn- [46]; KHO žan- [46]; KAL jhon- [46]; MAY porz- [46]; TOR janū- [46]; DRS dașțt[209]; AST dașțth- [209]; GUR daṣ̆t- [209]; KOH laçh- [513], si- [518]; GOW(?); BSK jān- [46].

46 leaf: KSM pan [47]; GLT pāțu [47]; BRK pani [47]; PHL palā [234]; GAW phața [47]; PSH pațā [47]; KHO ç̣han [368]; KAL p(ŕ) ũ [47]; MAY paṇd [47]; TOR pāṣ̆ [-4]; DRS pațo [47]; AST paṭo [47]; GUR pațu [47]; KOH pațo [47]; GOW paț(h) [47]; BSK paג [-3].

47 lie: KSM šong- [48], d̦āph trāw- [466]; GLT žek bo- [140], țām bō- [507]; BRK svay- [439]; PHL dhreg th- [140]; GAW dada ș̣a- [274]; PSH phal- [332]; KHO por- [309]; KAL dhrek as- [140]; MAY lui- [455]; TOR bāngde baž- [483]; DRS dil bō- [521]; AST jek bō- [140]; GUR țam bō- [507]; KOH žêk bō- [140]; GOW par- [309]; BSK likeg- [140], dayar da- [528].

48 liver: KSM krehnamāz [49]; GLT yūm [141]; BRK gyim [141]; PHL jhayār [-4]; GAW andec

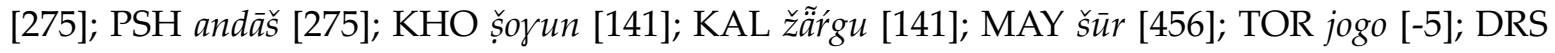

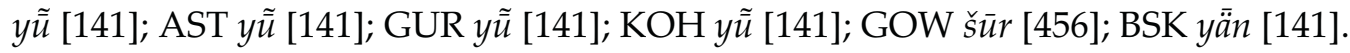

49 long: KSM z'ūṭh [50]; GLT žigu [142]; BRK žìgo [142]; PHL drhigo [142]; GAW ligala [142]; PSH ūṣ̌ [333]; KHO drung [142]; KAL drīga [142]; MAY žig [142]; TOR jig [142]; DRS jino [142]; AST žigu [142]; GUR jigu [142]; KOH žigo [142]; GOW žug [142]; BSK līg [142].

50 louse: KSM zuw [51]; GLT jū [51]; BRK žva [51]; PHL jhī [51]; GAW zum [51]; PSH žū [51];

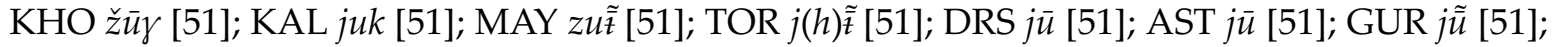

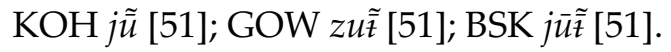

51 man: KSM marid [-5]; GLT mušā [143]; BRK muš [143]; PHL mī̌s [143]; GAW lāuṛī [276]; PSH wīr [334], māṣsu [143]; KHO moš [143]; KAL puruș [406]; MAY māš [143]; TOR māṣ̌ [143]; DRS muša [143]; AST muša [143]; GUR mušā [143]; KOH mušā [143]; GOW mēš [143]; BSK mī̌s [143].

52 many: KSM wāryāh [53], s'äthāh [54]; GLT bodu [170], tušar [210], lāwo [277]; BRK bede [170]; PHL bìdu [144]; GAW lāu [277]; PSH bū [170]; KHO bo [170]; KAL bo [170]; MAY cei [484], žhau [457]; TOR čar [484], gan [485]; DRS lāu [277]; AST lā [277]; GUR tišār [210], lā [277]; KOH lā [277]; GOW j(h)o [514]; BSK bār [53].

53 meat: KSM māz [55]; GLT mos [55]; BRK mōs [55]; PHL mhās [55]; GAW anda [278]; PSH pai [335]; KHO pušur [369]; KAL mos [55]; MAY māsī [55]; TOR mās [55]; DRS mōst [55]; AST mōs [55]; GUR mōs [55]; KOH mōs [55]; GOW mās [55]; BSK mās [55].

54 moon: KSM zūn [56]; GLT yūn [56]; BRK gyun [56]; PHL yūn [56]; GAW māsoi [279]; PSH māi

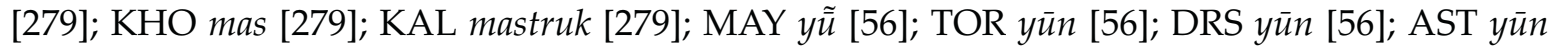
[56]; GUR yūn [56]; KOH yūn [56]; GOW y $\tilde{\tilde{u}}$ [56]; BSK yusun [56]. 
55 mountain: KSM bāl [57], sangur [58]; GLT čhār [212], khạ̣ [145]; BRK žuๆ [440], bār [441]; PHL khān [145], mou [235]; GAW dār [280]; PSH dār [280]; KHO an [370], zom [371]; KAL sun [407]; MAY khān [145]; TOR khān [145]; DRS šāy [493], khāṇ [145]; AST ç̣hịs [-3]; GUR khọ̣ [145]; KOH khạ̣ [145]; GOW khān [145]; BSK khan [145].

56 mouth: KSM às [59]; GLT ã̃ [59]; BRK ūzi [59]; PHL dhūt [236]; GAW hãasi [59]; PSH dōr [336];

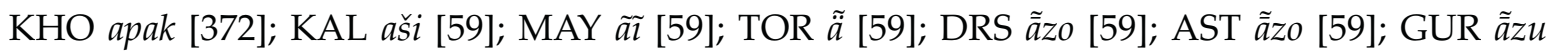

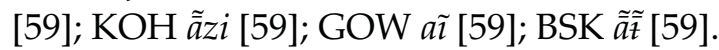

57 name: KSM nāw [60]; GLT nom [60]; BRK nu [60]; PHL nõ [60]; GAW nam [60]; PSH nām [60]; KHO nam [60]; KAL nom [60]; MAY nã [60]; TOR nām [60]; DRS nōm [60]; AST nōm [60]; GUR nōm [60]; KOH nūm [60]; GOW nav [60]; BSK nām [60].

58 neck: KSM nāl [61], kàr [62]; GLT șak [213]; BRK gri [442]; PHL mã̃tu [146]; GAW manda [146]; PSH mandā [146]; KHO būk [-5]; KAL bis [426]; MAY ș̣ākh [213]; TOR mār [146], čonjo [486]; DRS čhagan [494], žakū [495]; AST șak [213]; GUR șak [213], šọnu [508]; KOH șak [213]; GOW maṭhi [146]; BSK mạ̣ [146].

59 new: KSM now [63]; GLT nāwu [63]; BRK nū [63]; PHL nāwu [63]; GAW nuฑga [63]; PSH nūyga [63]; KHO noy [63]; KAL nhok [63]; MAY naũ [63]; TOR nam [63]; DRS nāo [63]; AST naũ [63]; GUR nã [63]; KOH nõ [63]; GOW nā [63]; BSK nam [63].

60 night: KSM rāt [-6]; GLT rāti [-2]; BRK bēlday [281]; PHL rōt [-5]; GAW yel [281]; PSH wyāl [281]; KHO čhuy [374]; KAL rāt [-1]; MAY rāl [-5]; TOR jhìm [487]; DRS rāti [-3]; AST rāti [-4]; GUR rāti [-3]; KOH rāti [-3]; GOW rāu [-4]; BSK rāt [-4].

61 nose: KSM nas [64]; GLT natu [64]; BRK nūto [64]; PHL nāst [64]; GAW nāsī [64]; PSH nās [64]; KHO niskar [64]; KAL načur [64]; MAY nathur [64]; TOR nāt [64]; DRS noto [64]; AST nato [64]; GUR notu [64]; KOH nothi [64]; GOW nath [64]; BSK näzōr [64].

62 not: KSM ni [65]; GLT nē [65]; BRK na [65]; PHL na [65]; GAW na [65]; PSH ne [65]; KHO no [65]; KAL ne [65]; MAY nā [65]; TOR nā [65]; DRS nuš [65]; AST na [65]; GUR ne [65]; KOH na [65]; GOW na [65]; BSK na [65].

63 one: KSM akh [66]; GLT ek [66]; BRK èk [66]; PHL āk [66]; GAW yak [66]; PSH ì [66]; KHO ì [66]; KAL ek [66]; MAY ek [66]; TOR e(k) [66]; DRS ek [66]; AST ek [66]; GUR ek [66]; KOH ek [66]; GOW ek(h) [66]; BSK ak [66].

64 person: KSM mohn'uw [67]; GLT mānužu [67]; BRK mušpo [147]; PHL monuṣ̆ [67]; GAW mānuṣ̌ [67]; PSH ādam [-4]; KHO roy [375], žun [295]; KAL moč [147]; MAY māšs [147], pičā [458]; TOR māṣ [147]; DRS manūžo [67]; AST manūžo [67]; GUR manūju [67]; KOH manūžo [67]; GOW $m o ̄ s ̣$ [67]; BSK mī̌s [147].

65 rain: KSM rūd [68]; GLT ažu [148]; BRK čharpa [-5]; PHL baṣ̌ [237]; GAW waṣ̌ [237]; PSH dāmān [337]; KHO boṣ̌ik [237]; KAL bāṣ̌ik [237], dira [408]; MAY až [148]; TOR āg(h)ā [148]; DRS ažo [148], mẽ̃ [496]; AST ažo [148]; GUR aju [148]; KOH ažo [148]; GOW až [148]; BSK āga [148].

66 red: KSM wozul [69]; GLT lolyu [149]; BRK lōdo [149]; PHL lohilo [149]; GAW lutura [149]; PSH ș̣ọāk [338]; KHO kruy [376]; KAL laçhia [296]; MAY lhamlu [149]; TOR la(g)hūr [149]; DRS lōlo [149]; AST lōlo [149]; GUR lōlu [149]; KOH lhīlo [149]; GOW lhyū [149]; BSK lōu [149].

67 road: KSM wat [-7]; GLT pon [150]; BRK pun [150]; PHL pand [150]; GAW phont [150]; PSH pand [150]; KHO pon [150]; KAL p(h)on [150], biriči [410]; MAY pan [150]; TOR pān [150]; DRS pon [150]; AST pon [150]; GUR pon [150]; KOH pon [150]; GOW pan(a) [150]; BSK pan(d) [150]. 
68 root: KSM mūl [70]; GLT mūli [70]; BRK pațtaq [-6]; PHL neṛī [151]; GAW nār [151]; PSH ałgī [339]; KHO mūl [70], iwak [377]; KAL istnos [411], yawak [377]; MAY naĩ [151]; TOR nā [151]; DRS čhiliș [-4]; AST čhiriṣ̌ [-5]; GUR čhiriṣ̌ [-4]; KOH čheriṣ̆ [-4]; GOW z(h)ēlya(h) [469]; BSK nēr [151].

69 round: KSM duloma [71]; GLT bidiru [214]; BRK dĩdūro [443]; PHL pindūura [238]; GAW (?); PSH (?); KHO pindoru [238]; KAL pinduri [238]; MAY didōọ [443]; TOR barūl [488]; DRS kirkiro [497]; AST dịūuro [443]; GUR dudūuru [443]; KOH dịūuro [443]; GOW (?); BSK (?).

70 sand: KSM sekh [72]; GLT sigal [72]; BRK sìri [72]; PHL sigal [72]; GAW sĩu [72]; PSH sēo [72]; KHO šułur [72]; KAL šigou [72]; MAY sigal [72]; TOR sigal [72]; DRS sinel [72]; AST sinel [72]; GUR sinil [72]; KOH sigal [72]; GOW sigal [72]; BSK sigit [72].

71 say: KSM wan- [73], dap- [74]; GLT ray- [215]; BRK rāz- [215]; PHL manū- [152]; GAW ža[282]; PSH mar- [152], daf- [74]; KHO re- [378]; KAL mãtr- [152], wonj- [412]; MAY man- [152], ban- [73]; TOR ban- [73]; DRS raj- [215]; AST raz- [215]; GUR raj- [215]; KOH raz- [215]; GOW al[519]; BSK män- [152].

72 see: KSM wučh- [75], deš- [76]; GLT paš- [154], ç̣ak- [498]; BRK ski- [444]; PHL daç̌h- [76]; GAW bāli- [191], ta- [283]; PSH dè- [340]; KHO lol- [299], poš- [154]; KAL jih- [340], paš- [154]; MAY nahal- [191], payš- [154]; TOR paš- [154], diț- [76], bū- [516]; DRS ç̣ak- [498], paš- [154]; AST çak[498]; GUR paš- [154], ç̣ak- [498]; KOH paš- [154], ç̌ak- [498]; GOW pašỗ [154]; BSK paš- [154], biç̣h- [75], liç̣h- [76].

73 seed: KSM byol [77]; GLT bi [77]; BRK bi [77]; PHL phalūru [239], bī [77]; GAW bìu [77]; PSH bì [77]; KHO bì [77]; KAL bi [77]; MAY bì [77], āyiri [459]; TOR biš [77]; DRS bì [77]; AST bì [77]; GUR $b \bar{\imath}$ [77]; KOH $b \bar{\imath}$ [77]; GOW $b \bar{\imath}$ [77]; BSK $b \bar{\imath}$ [77].

74 sit: KSM beh- [78]; GLT bay- [78]; BRK bay- [78]; PHL bheš- [78]; GAW niši th- [284]; PSH nē[284]; KHO niš- [284]; KAL nis- [284]; MAY bhay- [78]; TOR bhay- [78]; DRS bi- [78]; AST bi- [78]; GUR bi- [78]; KOH bi- [78]; GOW biš- [78]; BSK bäy- [78].

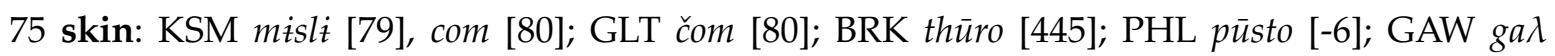
[285]; PSH pațalā [312]; KHO post [-6]; KAL post [-2]; MAY cām [80]; TOR čàm [80]; DRS čom [80]; AST čom [80]; GUR čom [80]; KOH čom [80]; GOW cam [80]; BSK čam [80].

76 sleep: KSM šong- [48], nendir kar- [82]; GLT so- [174]; BRK su- [174]; PHL sū- [174]; GAW גap ker- [174], pēi- [286]; PSH ōrač a- [341]; KHO ore- [341], por- [379]; KAL prasu- [174], dududi- [413]; MAY sut bi- [174]; TOR hub- [174], nin kow- [82]; DRS sō- [174]; AST sō- [174]; GUR sō- [174]; $\mathrm{KOH}$ nīṣ tho- [82]; GOW sõ [174]; BSK nīn bač- [82].

77 small: KSM lokuț [83]; GLT čuṇu [216], kholu [217]; BRK seno [446], āpo [447]; PHL lohoko [83]; GAW pola [287]; PSH sūr [258]; KHO ceq [-7]; KAL alūyak [414], čutyak [415]; MAY lakh [83]; TOR luṭ [83]; DRS čuṇo [216]; AST khuṭu [504], čuno [216]; GUR čuṇu [216]; KOH čuṇo [216]; GOW luku [83]; BSK lukuṭ [83], čunuṭ [216].

78 smoke: KSM dìh [84]; GLT dum [84]; BRK dū [84]; PHL dhūmi [84]; GAW dum [84]; PSH dūm [84]; KHO kūšun [380]; KAL dhūm [84]; MAY duhã [84]; TOR d(h)imī [84]; DRS dūm [84]; AST

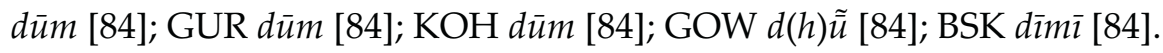

79 stand: KSM woth- [85]; GLT uthyo- [85], čoko bō- [509]; BRK uth- [85]; PHL utth- [85]; GAW uṣ̆ț- [85]; PSH žān h- [342]; KHO riph- [381]; KAL čișț- [85]; MAY oēlay bi- [460]; TOR ị̣i ho- [85]; DRS uth- [85]; AST hun bō- [505]; GUR čok bō- [509]; KOH uth- [85], čoko bō- [509]; GOW (?); BSK itthi- [85]. 
80 star: KSM tāruk [86]; GLT tāru [86]; BRK tūri [86]; PHL toru [86]; GAW tāra [86]; PSH astārīč [86]; KHO istāri [86]; KAL tāri [86]; MAY tār [86]; TOR tā [86]; DRS tāro [86]; AST tāro [86]; GUR tāru [86]; KOH tāro [86]; GOW tār [86]; BSK tār [86].

81 stone: KSM kan' [87]; GLT bātt [155]; BRK nāro [448]; PHL bāt [155]; GAW waț [155]; PSH wār [155]; KHO boxt [155]; KAL bat [155]; MAY bāt [155]; TOR bāt [155]; DRS bat [155]; AST baț [155], gìri [517]; GUR baț [155]; KOH baț [155]; GOW baț(h) [155]; BSK baț [155].

82 sun: KSM sirī [88]; GLT sūri [88]; BRK sūri [88]; PHL sūri [88]; GAW sūri [88]; PSH sur [88]; KHO yor [382]; KAL sūri [88]; MAY suri [88]; TOR sī [88]; DRS sūri [88]; AST sūri [88]; GUR sūri [88]; KOH sūri [88]; GOW sūri [88]; BSK sìr [88].

83 swim: KSM chanțh wāy- [480]; GLT tam do- [-3]; BRK škēlith- [-7]; PHL bahayēygi de- [89]; GAW lōe $\lambda i$ - [288]; PSH lèw- [288]; KHO utanu usne- [156]; KAL waz- [-3]; MAY dhay- [460], guìli di- [461]; TOR lāmo dew- [-6]; DRS nōš- [499]; AST tam dō- [-5]; GUR nūš di- [499]; KOH tar[523]; GOW lhāmbo diō [-5]; BSK sãnäțe dì- [156].

84 tail: KSM dumbi [90]; GLT phočo [219]; BRK piči [219]; PHL lamēți [90]; GAW limoța [90]; PSH lìm [90]; KHO rum [90]; KAL dhamŕei [90]; MAY lawãt [90]; TOR lamāt [90]; DRS lamuṭi [90]; AST lamoți [90]; GUR lamōțu [90]; KOH lamțō [90]; GOW lamuț(h) [90]; BSK lumaṭ [90].

85 that: KSM huh [91], suh [92]; GLT o [91], ro [220]; BRK alo [91], so [92]; PHL aro [91], haso [92]; GAW ase [92], t- [157]; PSH ò [91], satē [92]; KHO hase [92]; KAL ala [91], (a)sa [92]; MAY su [92]; TOR se [92], tes [157]; DRS parāo [500]; AST à [91]; GUR à [91]; KOH asa [92]; GOW so [92]; BSK aș̌ẽ [92], tath $\tilde{\bar{t}}$ [157].

86 this: KSM yih [93], nom [240]; GLT anu [240]; BRK homo [449], alam [240]; PHL anu [240]; GAW en [93], woi [240]; PSH äe [93], elo [240]; KHO haya [93]; KAL ia [93]; MAY ș̌ $\tilde{u}$ [93]; TOR $\ddot{a}$ [93]; DRS anuh [240], žo [501]; AST anuh [240]; GUR anu [240], žo [501]; KOH àe [93]; GOW ai [93]; BSK äỹ [93], athã [240].

87 thou: KSM ci [95]; GLT $t u$ [95]; BRK ti [95]; PHL $t u$ [95]; GAW $t u$ [95]; PSH $t \bar{u}$ [95]; KHO $t u$ [95]; KAL tu [95]; MAY tu [95]; TOR tù [95]; DRS tuh [95]; AST tuh [95]; GUR tu [95]; KOH tu [95]; GOW tu [95]; BSK tu [95].

88 tongue: KSM zew [96]; GLT jip [96]; BRK gìp [96]; PHL jib [96]; GAW zib [96]; PSH jib [96]; KHO ligini [383]; KAL jip [96]; MAY zib [96]; TOR jib [96]; DRS jip [96]; AST jip [96]; GUR jip [96]; KOH jip [96]; GOW ziba [96]; BSK jib [96].

89 tooth: KSM dand [97]; GLT don [97]; BRK dani [97]; PHL dān [97]; GAW dant [97]; PSH dānd [97]; KHO don [97]; KAL dandoŕyak [97]; MAY dān [97]; TOR dān [97]; DRS don [97]; AST don [97]; GUR don [97]; KOH don [97]; GOW dan [97]; BSK dan [97].

90 tree: KSM kul [98]; GLT tom [158], muțo [241]; BRK laqčuks [-8]; PHL muțt [241]; GAW muṭa [241]; PSH kurāa [343]; KHO kan [384]; KAL muṭ [241]; MAY gī [462]; TOR thām [158]; DRS byeĩ [502]; AST tom [158]; GUR tom [158]; KOH tom [158], muṭho [241]; GOW biç̣ [515]; BSK tam [158].

91 two: KSM zi [99]; GLT $d u$ [99]; BRK $d \bar{u}$ [99]; PHL $d \bar{u}$ [99]; GAW $d u$ [99]; PSH $d \bar{o}$ [99]; KHO jū [99]; KAL $d \bar{u}$ [99]; MAY du [99]; TOR dū [99]; DRS du [99]; AST du [99]; GUR $d \bar{u}$ [99]; KOH $d \bar{u}$ [99]; GOW $d u$ [99]; BSK dū [99].

92 walk (go): KSM gach- [100], pak- [101]; GLT yay- [221], g- [100], buž- [428]; BRK bo- [428], gi[100]; PHL čo- [159], g- [100], bay- [428]; GAW di- [221], go [100]; PSH g- [100], par- [221]; KHO 
bo- [221], bar [100]; KAL par- [221], gala [100]; MAY gā- [100], bi- [428], til- [462]; TOR baž- [428], $g \bar{a}$ [100]; DRS boj- [428], yaž- [221], gā- [100]; AST buj- [428], yaz- [221], gā- [100]; GUR boj- [428],

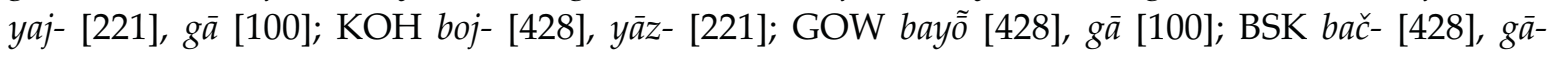
[100], čō- [159].

93 warm: KSM tot [102], wušun [103]; GLT tātu [102]; BRK tāto [102]; PHL tāto [102]; GAW tapo [102]; PSH tapē [102]; KHO peç [385], tāf [102]; KAL dūdū [416], tapala [102]; MAY tat [102]; TOR tāt [102]; DRS tatto [102]; AST tatto [102]; GUR tatu [102]; KOH tato [102]; GOW tat(h) [102]; BSK uṣ̌un [103], tapijāl [102].

94 water: KSM āb [104]; GLT wai [104]; BRK va [104]; PHL wì [104]; GAW aū [104]; PSH warg [344]; KHO uү [104]; KAL uk [104]; MAY vī [104]; TOR $\bar{u}$ [104]; DRS woi [104]; AST woi [104]; GUR voi [104]; KOH woi [104]; GOW vī [104]; BSK $\bar{u}$ [104].

95 we: KSM as' [105]; GLT be [193], as- [105]; BRK ba [193], as- [105]; PHL be [193], as- [105]; GAW amō [105]; PSH hamā [105]; KHO ispa [105]; KAL abi [105]; MAY be [193], z $\tilde{\tilde{a}}$ [105]; TOR mho [105]; DRS be [193], as- [105]; AST be [193]; GUR be [193], as- [105]; KOH be [193], as- [105]; GOW be [193], as- [105]; BSK mã [105].

96 what: KSM kyāh [106]; GLT jēk [222]; BRK ye [222]; PHL ga [106]; GAW kī [106]; PSH kāl [106]; KHO kya [106]; KAL kīa [106]; MAY gi [106]; TOR kā [106]; DRS jok [222]; AST yōk [222]; GUR jōk [222]; KOH jō [222]; GOW gi [106]; BSK kā [106].

97 white: KSM čhot [107], pron [108]; GLT šeu [223]; BRK šō [223]; PHL pānāaru [108]; GAW wuzala [176]; PSH ç̣helāk [107]; KHO išperu [223]; KAL gōra [417]; MAY panar [108]; TOR ujal [524]; DRS șyyō [223]; AST šêo [223]; GUR šō [223]; KOH šō [223]; GOW uzal [524]; BSK panar [108].

98 who: KSM kus [109]; GLT kō [109]; BRK ko [109]; PHL ko [109]; GAW kara [109]; PSH kī [109]; KHO ka [109]; KAL kura [109]; MAY kā [109]; TOR kām [109]; DRS kōi [109]; AST koi [109]; GUR kōe [109]; KOH koe [109]; GOW kū [109]; BSK kam [109].

99 woman: KSM triy [110]; GLT čei [110]; BRK ç̣iga [110]; PHL kurī [425]; GAW šigalī [110]; PSH astrī [110]; KHO kimeri [386]; KAL istriža [110]; MAY ghar $\tilde{\bar{t}}$ [-6]; TOR ç̣hī [110]; DRS čẽ [110]; AST čei [110]; GUR čei [110]; KOH čei [110]; GOW mulay [516]; BSK is [110].

100 yellow: KSM l'odur [111]; GLT haližu [111]; BRK haldūro [111]; PHL zyär [-7]; GAW phiala [-2]; PSH lūm [345]; KHO zēç [-8]; KAL badu [418]; MAY pīl [-7]; TOR čono [489]; DRS gūuro [503]; AST komūmo [506]; GUR kumūmu [506]; KOH pīlo [-5]; GOW pīl [-6]; BSK čōner [489].

M. E. VASILYEV, A. I. KOGAN. On the East Dardic language group.

The paper addresses the issue of the genetic classification of Dardic languages. Special attention is paid to the problem of genetic relations between the languages that are traditionally grouped together as "East Dardic". To solve this problem, two different lexicostatistical approaches are suggested: the specific version of the neighbour-joining algorithm and a statistical method, based on the average deviation criterion. After the comparative analysis of the resulting genetic trees the authors discuss the issue of the historical background and finally conclude that the "East Dardic" group forms a single and separate branch among the Dardic languages.

Keywords: Dardic languages, language classification, historical phonology, etymology, lexicostatistics, neighbour-joining method. 
